\title{
Research on the Peer Behavior of Local Government Green Governance Based on SECI Expansion Model
}

\author{
Hongda Liu $\left(\mathbb{D}\right.$, Pinbo Yao $\mathbb{D}^{\mathrm{D}}$, Xiaoxia Wang, Jialiang Huang and Liying Yu *(D) \\ School of Management, Shanghai University, Shanghai 200444, China; liuhoda@shu.edu.cn (H.L.); \\ yaopinbo@shu.edu.cn (P.Y.); charmian@shu.edu.cn (X.W.); HuangJL@shu.edu.cn (J.H.) \\ * Correspondence: yuliying@shu.edu.cn
}

Citation: Liu, H.; Yao, P.; Wang, X.; Huang, J.; Yu, L. Research on the Peer Behavior of Local Government Green Governance Based on SECI Expansion Model. Land 2021, 10, 472. https://doi.org/10.3390/land10050472

Academic Editors: Maciej J. Nowak,

Giancarlo Cotella and

Przemysław Śleszyński

Received: 19 March 2021

Accepted: 28 April 2021

Published: 1 May 2021

Publisher's Note: MDPI stays neutral with regard to jurisdictional claims in published maps and institutional affiliations.

Copyright: (c) 2021 by the authors. Licensee MDPI, Basel, Switzerland. This article is an open access article distributed under the terms and conditions of the Creative Commons Attribution (CC BY) license (https:// creativecommons.org/licenses/by/ $4.0 /)$.

\begin{abstract}
Exploring the cohort behavior of local governments in green governance from the perspective of knowledge management can help promote the implementation of new development concepts. This article firstly explains the differentiation logic of local governments' green governance cohort behavior based on the SECI expansion model. Secondly, by constructing a dynamic evolutionary game model, the conditions for the formation of positive and negative cohorts are analyzed. Finally, corresponding countermeasures are proposed. The results show that under the effect of knowledge management, the explicit and tacit knowledge, such as green governance ability and willingness of local government transform into each other, finally differentiates into four kinds of peer behavior states. Willingness stimulation, learning effect perception, complementary knowledge stock, knowledge synergy income, cooperation value-added income, punishment and reputation loss increase, which promotes local government green governance into a positive-peer state. Knowledge learning effect only exists in the early and middle stages of green governance, while the knowledge spillover effect has a more significant impact in the later stage of green governance; a higher gap between explicit knowledge and tacit knowledge, and a lower level of tacit knowledge and explicit knowledge, are conducive to the formation of positive-peer status.
\end{abstract}

Keywords: SECI expansion model; local government; green governance; peer behavior; green development

\section{Introduction}

Implementing the 'new development concept' is the key to the high-quality development of China's economy [1]. With the increasing downward pressure on China's economy and the gradual emergence of ecological adverse effects, the extensive economic growth mode is challenging to meet the requirements of China's high-quality economic transformation, and green governance has become a meaningful way to solve the problem of green development [2]. Green governance is a community of green governance based on the principles of mutual trust and mutual reliance and sharing, guided by the concept of green development, to cooperate and govern public affairs. In order to achieve a harmonious and sustainable governance process of economy, politics, society, culture, and ecology, the grassroots government is the core subject of green governance [3-6]. However, green governance has many characteristics, such as thorny subjects and broad fields, which require the effective promotion of government subjects [7]. Based on such a realistic background, the research of green governance based on the level of local government will help implement top-level design into the practical level and provide reference ideas for standardizing local government behavior and realizing scientific and rational decision-making.

The green governance work of local government has gradually deepened from a point to an area. At the beginning of the 13th five-year plan, the development concept of innovation, coordination, green, open, and sharing laid the thinking and focus of China's future development. It solved the problems of regional ecosystem degradation and low-quality 
economic development to a great extent. Green governance has become a vital integration practice of the new development concept [8]. The demonstration experience of ecological and green integration development in the Yangtze River Delta shows that green governance is the critical measure for building a modern economic system, optimizing the economic structure and transforming the development mode and power. The realization of efficient green governance will win significant opportunities for the region to seize future development opportunities [9]. In the middle and late period of the 13th five-year plan, successful attempts in some areas have made green governance a tool to promote backward area economic development to 'overtake' and improve quality and efficiency. Local governments show prominent characteristics of 'mutual competition' and 'mutual observation', which leads to the formation of green governance peer behavior [10]. Nevertheless, there is an economic question implied here: Why do local governments have assertive peer behavior in green governance? There are two main reasons: first, under the premise of the central government's strong emphasis on the 'new development concept', local governments have less room for decision-making, so peer behavior is more pronounced. Secondly, under the role of 'scale competition', the local government's individual behavior is more affected by group behavior. The successful cases of green governance significantly 'intervene' in the decision-making of local government behavior. Therefore, the local government's peer behavior in green governance is stronger than the convergence of previous decision-making, and its motivation and evolution logic are more worthy of attention and discussion. In particular, green governance cannot be achieved overnight. Blind conglomeration and perceptual decision-making may cause more economic losses to local governments, which is incomparable with the previous government management peer behavior. In view of this, this paper intends to build a systematic analysis framework, use knowledge management theory to analyze the logic of local government green governance, and put forward the peer effect and different peer types. Finally, based on the evolutionary game model, this paper clarifies the impact of knowledge management on the green governance peer behavior of the local government, promotes the local government's reasonable peer behavior, and enhances the peer effect.

\section{Theoretical Analysis}

\subsection{Formation Logic of Peer Behavior of Green Governance}

After the reform of the tax-sharing system, China's economic development entered a new era. Local governments now undertake more social responsibilities while fulfilling their economic construction responsibilities. Protecting the interests of the jurisdiction and realizing the balance of power and responsibility have become the local governments' action logic. Under the guidance of this action logic, the dynamic mechanism of social operation has become the critical element of effective, healthy, and sustainable management action of local governments [11]. Local governments achieve orderly and efficient social management through the external core links of power source development, power conversion, power distribution, power feedback, and other mechanisms [12]. As the local government's dynamic response to comprehensively deepen reform and optimize governance capability, green governance has a robust local government distinctive brand. Green governance exists in the form of system design and is regarded as a combination of 'package' behavior and capability [13]. Under the social operation dynamic mechanism, green governance takes the local government as the main body and the construction of regional ecological civilization environment as the power source. Based on the extension of 'package' behavior and ability and the integration or exclusion of the interest demands of various subjects, it forms the dynamic mechanism operation field of gravitation, thrust, resistance, and pressure [11].

Through the guidance of four force fields of gravitation, thrust, resistance, and pressure, local governments gradually form the cooperative or autonomous social operation dynamic mechanism of green governance. The action's feedback is characterized by cooperative or autonomous governance action. Based on the evolutionary stability of cooperative 
or autonomous governance action, green governance peer behavior is formed. From the perspective of gravity, the common interests of local governments lead the two sides to strengthen the cooperation relationship, and the increase of cooperation income leads to the strengthening of the green governance cooperation dynamic mechanism [14]. Unlike the endogenous gravitation caused by internal interests, the thrust comes more from the external environment of green governance. On the one hand, the guidance of macro value and the implementation of the top-level system bring great guidance to the practice of green governance. It ensures the development of green governance through the mechanism of error correction and fault tolerance $[15,16]$. On the other hand, with the promotion of the green governance culture system, the participation of green governance subjects and the flow of various elements break the resource and administrative barriers of green governance among governments and promote the stability of the green governance cooperation dynamic mechanism [17,18]. As the key field of the formation of the green governance cooperation dynamic mechanism, gravity and thrust are a positive force. However, due to the differences in the basis of green governance and the contradictions in the distribution of government benefits, the characteristics of the 'rational economic man' of local governments are increasingly obvious. The resistance conflict between the maximization of local interests and cooperative benefits is becoming more and more acute [11]. Simultaneously, the differentiation of co-construction, co-governance, and sharing of green governance is serious, and the independent dynamic mechanism of local government green governance gradually dominates the government management behavior [19]. This kind of governance resistance becomes the reverse force of the formation of the green governance cooperation dynamic mechanism. Whether it is to protect the interests of the jurisdiction optimization or out of rational decision-making, local governments need to promote green governance. However, there is a practical problem: the real change brought by green governance is not yet expected, but the local government has been burdened with higher governance pressure. On the one hand, this kind of pressure makes the local governments choose to follow other districts' management modes, trying to share the pressure and reduce the difficulty of decision-making. On the other hand, it causes some local officials to make narrow decisions, compressing the production cycle of governance achievements with expansionary governance to realize subversive development. Pressure causes local government green governance to be more competitive and observant, tends to form a cooperative dynamic mechanism of green governance, or reverses and solidifies the independent dynamic mechanism of green governance, which is reflected as an uncertain force. The action mechanism of each force field is shown in Figure 1.

With the shaping of the four force fields and the stability of local government's cooperation or autonomous governance, local government's green governance presents the peer behavior. That is to say, local governments with similar geographical location, decision-making, and institutional environments form defensive administrative concepts, learn from each other or imitate each other in the process of green governance, and become a 'peer' collective. 


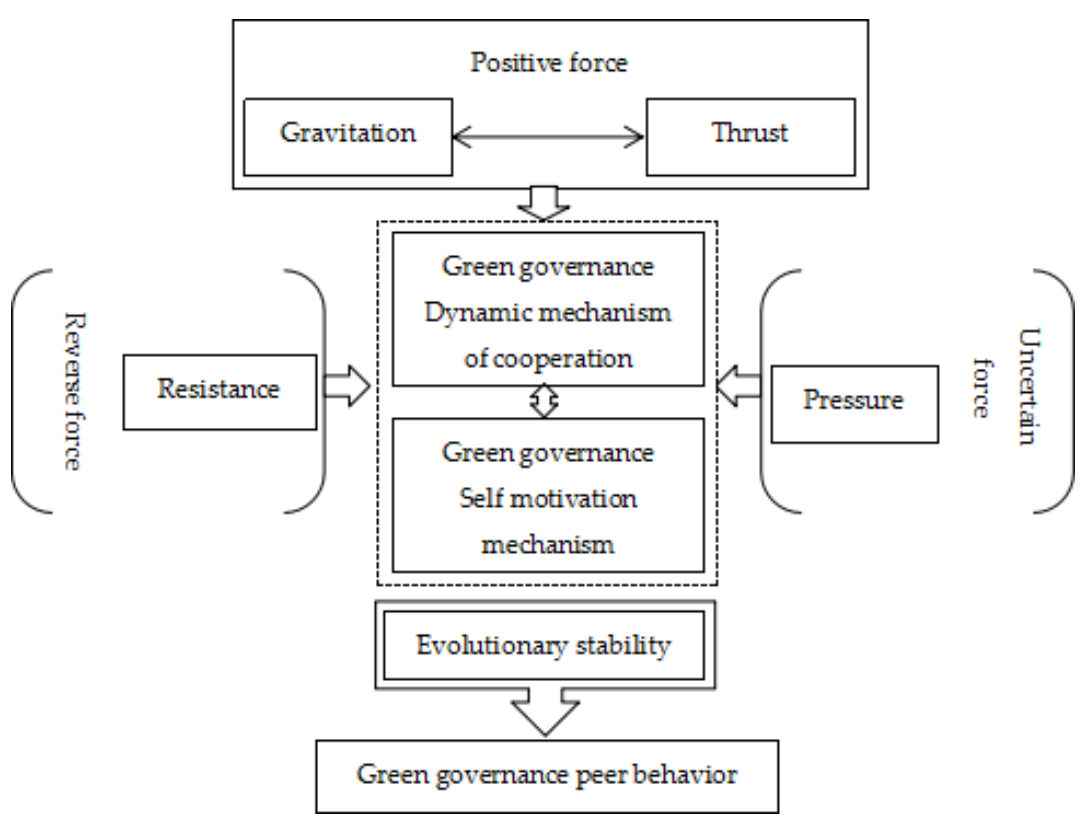

Figure 1. Logic diagram of the formation of the same peer behavior of green governance.

\subsection{The Necessity of Knowledge Management in Green Governance}

As a kind of management activity, the green governance of the local government needs substantial knowledge to assist in ensuring correct and effective decision-making. Scholars are concerned about the role of knowledge management in improving government work efficiency, and the research focuses on knowledge transfer and knowledge absorption and application [20]. Bonaccorsi [21] found that knowledge transfer has a positive effect on government-industry-university-research collaboration, and the process of knowledge transfer across organizations is the process of the government leading the industry-university-research collaboration. Koschatzky [22] tested the dynamic relationship between the knowledge transfer model and government collaborative innovation performance. He believes that the active transfer of knowledge, the coordination of objectives, and the correct transfer mode's determination will help improve the innovation output of collaborative organizations. Sun [23] discussed the path of knowledge heterogeneity and absorptive capacity on organizational performance from the perspective of organizational connection strength and believed that no matter what state the organization is in, it will accept heterogeneous knowledge resources. Horvat [24] used the knowledge absorption model to establish the corresponding index system, analyzed the coupling coordination of external knowledge absorption and utilization by government organizations, and emphasized knowledge acceptance. After the knowledge chain construction of knowledge transfer (output), knowledge absorption (input), and knowledge application (practice output) is completed, the expansion of sharing background further extends the knowledge chain and opens up the link of knowledge sharing [25] (input-output collaboration). Further integration of social attributes promotes the birth of a collaborative development knowledge sharing model [26], reducing the loss and capital cost in the process of knowledge transfer. Ahmed and Zhang analyzed the dilemma of knowledge sharing from social media [27] and alliance networks [28], respectively, and affirmed the positive contribution of knowledge sharing with alliance building. He emphasized the problem of knowledge embezzlement and unequal distribution of performance within the group and believed that the critical collaboration and breakthrough of knowledge is conducive to the stable development of the government collaborative development network.

To be sure, knowledge management not only promotes the scientific green governance of local governments but also promotes the formation of a government-led green governance collaborative system. However, there are many problems in the collaborative 
system: many organizations use the chain of knowledge transfer and knowledge sharing to carry out free riding actions [29] and conceal their destructive behaviors. On the one hand, enterprises use the collaborative system to reduce decision-making costs [30] and show their social decision-making as a positive transformation, but in fact they are not separate from the sequence of inefficient innovation and ineffective decision-making. On the other hand, with the enhancement of local government autonomy and self-interest, the conflicts of interests among regions and institutional environments pose challenges to green governance. Many local governments choose their behaviors to keep consistent with 'successful groups'. Therefore, although the green governance under this collaborative system reflects regional enterprises' collaborative development, it inevitably causes problems such as repeated construction and collective irrationality [31]. Although it has increased green social performance to a certain extent, negative-peer effects gradually emerge in areas with a poor institutional environment and weak innovation foundation [32]. Given the homogenization, inefficiency, and irrationality of local government's green governance, it is necessary to investigate the evolutionary logic of local government's green governance peer behavior from the perspective of knowledge management and explore how to use knowledge management to improve local government's green governance and enhance the decision-making efficiency of local government's peer behavior.

\section{The Differentiation Logic of Green Governance Peer Behavior Based on Knowledge Management}

\subsection{Local Governments and Their Green Governance Responsibilities}

From the perspective of heterogeneous government, this paper divides the local government into two types: focus local government (referred to as 'focus government') and non-focus local government (referred to as 'non-focus government') [33,34]. The focus government refers to the key actors and essential leaders in the development of regional linkage; non-focus government refers to the main participants with follow-up in regional linkage development. In Chinese practice, focus government is a local government with a high degree of regional development, a high level of central government attention, and a more prominent government capacity. Non-focus governments are local governments where regional development is relatively backward and government capacity is more limited. Focus and non-focus governments basically cover the main types of government in a metropolitan area or economic zone. In the Yangtze River Economic Belt, for example, the focus governments of Shanghai, Jiangsu, and Zhejiang have become the development leaders in the economic belt, while the non-focus governments of Yunnan, Guizhou, and Jiangxi generally undertake tasks such as industrial transfer and are in a state of development following.

As a significant project and action direction of local government development and transformation, green governance tends to be a kind of instrumental behavior and contains value [35]. This concept is embodied in the concept of 'green' and 'sustainable' development and tries to promote the society to form a 'green' development value orientation. Due to the high threshold of green development and the difficulty of implementation, local government governance behavior's 'instrumental' characteristics are strengthened. For example, the local government improved the corresponding democratic decision-making, administrative approval, social supervision, and other links and tried to support society in carrying out green transformation with more relaxed policies and softer ways.

\subsection{Mechanism of Knowledge Management on Green Governance of Local Government}

\subsubsection{Knowledge Management Promotes Green Governance Peer Behavior}

Due to the liquidity of knowledge, local governments are connected through the knowledge chain. In the process of the knowledge chain transmitting knowledge (knowledge transfer, knowledge absorption, and knowledge application), local governments' behaviors and ideas influence and act on each other. The feedback is characterized by the changes of the four major fields of dynamic social mechanism. From the perspective of 
gravity, there is a significant gap in economic and political resource endowment among local governments, which leads to differences in willingness and ability of green governance [11]. Through the moderating role of knowledge management, we can guide the matching orientation of green governance's will and ability, amplifying or reducing the gravitational effect and determining whether green governance is in the state of cooperation or autonomous dynamic mechanism. In the thrust field, the local government's external ability is limited, the system normative and rigid binding force are not strong, and the management efficiency and sustainable role are limited [11]. The moderating effect of knowledge management can guide the direction of explicit knowledge such as local government management ability, that is, enlarge or reduce the thrust effect and determine the final state of local government green governance. In the pressure field, local governments will be subject to the severe pressure of the central government's 'hierarchical pressure and key focus' institutional structure, resulting in the low willingness of green governance [11]. Moreover, the effective period of green governance is long, which may produce potential internal pressure on governance activities. The moderating effect of knowledge management can guide the direction of tacit knowledge such as local government's management intention, that is, amplify or reduce the pressure effect and ultimately affect the evolution and stability of green governance. As far as resistance is concerned, knowledge management's effectiveness will have an impact on the benefits of green governance of local governments. Through the dynamic balance between cooperative benefits and independent benefits of green governance, the leading dynamic mechanism of green governance is determined by amplifying or reducing the role of resistance. Therefore, knowledge management determines the trend of green governance peer behavior through the platform of four major fields.

\subsubsection{Knowledge Management Content of Green Governance}

In reality, in the face of mobile green development boundaries and diversified green governance demands, many local governments find it difficult to consider the unity of behavior idea and are forced by 'pressure cognition' and 'responsibility cognition' [36], leading to the conglomeration of green governance. In fact, the imbalance of local government's behavior idea is more manifested in the lack of knowledge management. As an essential means to promote the green governance of local governments, knowledge management undertakes the critical task of clarifying local government behavior and planning governance concepts. To some extent, the behavior and idea of local government is essentially a kind of knowledge resource. In green governance, some local governments' behaviors to society are presented in explicit forms such as policy planning and procedures, which is a kind of explicit knowledge. In contrast, local governments' ideas are presented in implicit forms such as management experience, willingness to green development, and value orientation, which are kinds of tacit knowledge. The local government's management of the two kinds of knowledge reflects its willingness and ability for green governance.

At present, the most classic knowledge transformation model in academia is the SECI model proposed by Nonaka, which contains four models for the mutual transformation of tacit knowledge and explicit knowledge. Most scholars at home and abroad have extended and expanded on this basis when doing relevant research in the field of knowledge management [37-40]. The SECI model can better explain the operation of knowledge [41], and the IDE-SECI extension model [42] can reflect the dynamic transformation process of internal and external knowledge in an organization. With this model's help, this paper describes the local government's knowledge management and explains the role of knowledge management in promoting green governance peer behavior. Generally speaking, knowledge is divided into four stages: socialization (S), externalization (E), combination (C), and internalization (I) [43].

In green governance, there is a knowledge collaborative transformation relationship among local governments, as shown in Figure 2. Knowledge can be divided into internal knowledge and external knowledge. Internal knowledge is the explicit and tacit knowledge 
of local governments, while external knowledge is the explicit and tacit knowledge of other local governments. The hidden knowledge reflects the concept of green governance of local government, including the attitude and attention to green governance. Explicit knowledge reflects the green governance behavior of the local government, including policy planning, management experience, technology orientation, human resources allocation ability, etc. The internal knowledge follows the IDE-SECI transformation mode. The four stages of knowledge circulation connect the knowledge interaction activities between local governments and enterprises within their jurisdiction, laying the foundation for the internal and external transformation of knowledge.

In the internal and external transformation of knowledge, there are two main types of local governments: social transformation and combinatorial transformation.

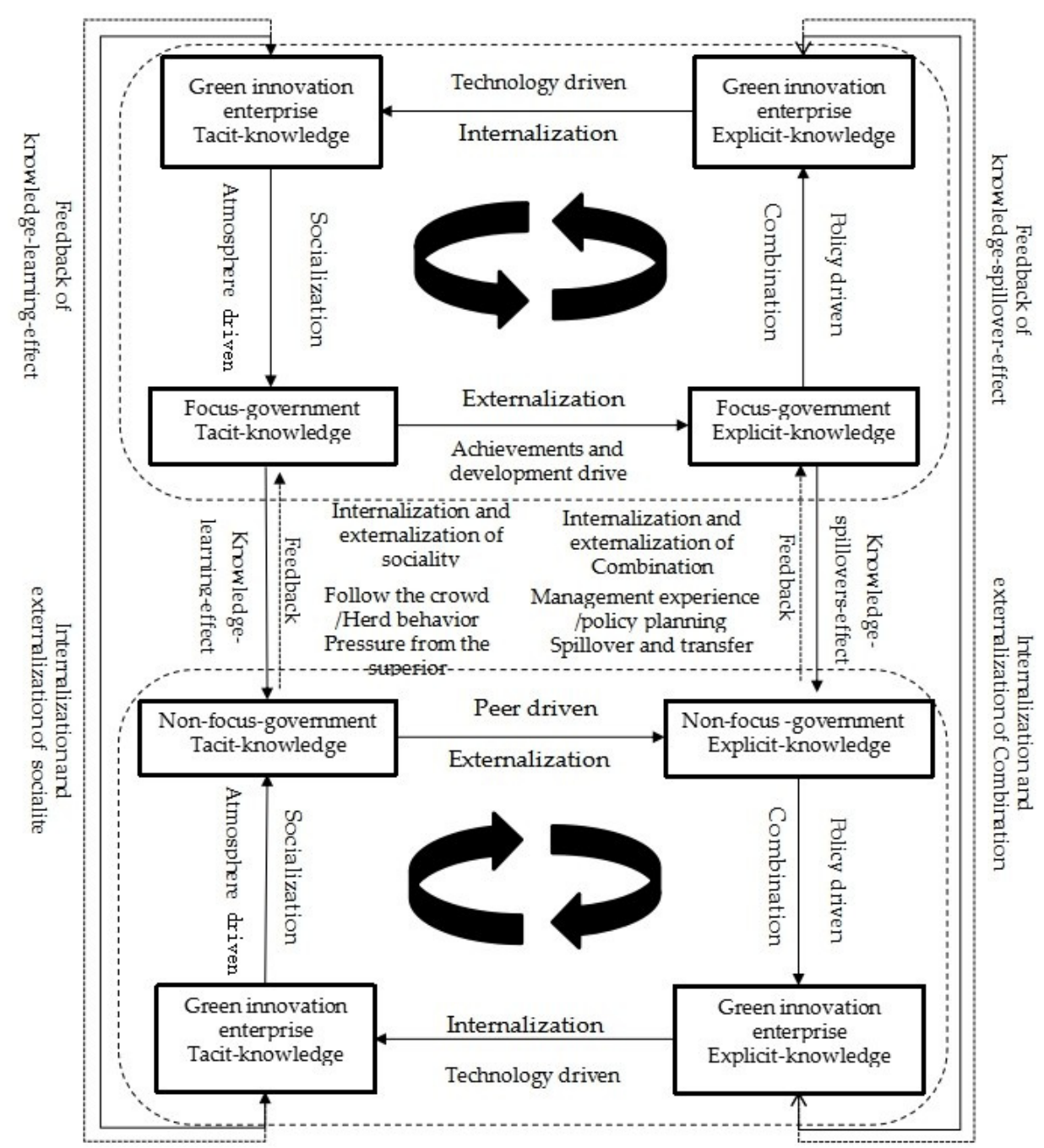

Figure 2. IDE-SECI simplified model of green governance peer behavior.

Social Transformation: Taking the non-focus government as an example, its green governance will be affected by the focus government. Non-focus governments often follow the focus government's development strategy, which is essentially the result of the tacit knowledge function of emotion and willingness [44]. This is defined as the relatively low organizational knowledge level and the relatively high level of organizational learning [45]. For the focus government, the output process of tacit knowledge is the social externalization of knowledge, which shows the 'low latitude' mobility of knowledge. In the process of knowledge output from focus government to non-focus government, the difference of governments' 'knowledge pool' will lead to feedback from the non-focus government to 
the focus government. In local development, there are leading or superior departments in non-focus government, which will produce crisis or stimulation to focus government and guide the focus government to strengthen green promotion willingness in weak departments. This process is social externalization of non-focus government knowledge. In Chinese practice, social transformation includes realistic forms such as regional government research missions and government exchange meetings. Based on these platform activities, local governments interoperate to achieve the will for green governance.

Combinatorial transformation: Non-focus government has some problems, such as lack of management experience, imperfect government systems, etc. Due to the knowledge spillover effect, the focus government will guide the non-focus government to supplement the explicit knowledge of green governance through industrial transfer, assistance, and docking, and will promote the development of regional green integration as the 'leader of the economic belt.' This knowledge flow process is the combined internalization of non-focus government knowledge [31]. In the process of capacity spillover, the nonfocus government will also give feedback to complementary knowledge to make up for some deficiencies of the focus government and to realize the combined externalization of knowledge [24]. In Chinese practice, the combined transformation includes the signing of regional specific policies, the establishment of cooperation parks, the construction of green high-tech interoperable development zones, and other realistic forms. Through these opportunities for cooperation, local governments are able to interact with each other to achieve green governance capacity.

When the green governance cooperation dynamic mechanism is formed among local governments under the joint action of social transformation and combinatorial transformation, the knowledge learning effect and knowledge spillover effect promote local governments to build green governance collaborative networks and form knowledge synergy effects. In the interactive process of the knowledge synergy effect, local governments further obtain the reciprocal effect of knowledge. The knowledge learning effect, knowledge spillover effect, knowledge synergy effect, and knowledge reciprocity effect constitute the cooperative benefits of local government green governance and promote the stable development of cooperative governance.

\subsubsection{Differentiation Process of Green Governance Conglomeration Behavior under Knowledge Management}

In green governance, the focus government and non-focus government, through the relationship of social transformation and combinatorial transformation of knowledge given by knowledge management, form the knowledge learning effect, knowledge spillover effect, knowledge synergy effect and knowledge reciprocity effect based on the stages of internalization of external knowledge, externalization of internal knowledge, and internal knowledge transformation. Based on the moderating effect of knowledge management, all kinds of knowledge effects adjust the level of explicit and tacit knowledge of local governments, which are characterized by the change of four major fields of dynamic social mechanism. Under the comprehensive action of gravity, thrust, pressure, and resistance, local governments eventually form green governance cooperation or autonomous power mechanisms and produce two strategies of cooperative governance or autonomous governance. Among them, the strategy of independent governance means that the subject is affected by resistance and refuses to transform knowledge in order to maintain the local 'rational interests'; the strategy of cooperative governance means that the subject is affected by gravity and thrust and chooses to transform knowledge and obtain the benefits of the knowledge effect. Due to the differences between focus government and non-focus government, focus government usually actively leads non-focus government to transform knowledge in cooperative governance. Non-focus governments generally take an active part in knowledge transformation, and both sides realize knowledge flow and change their own explicit and tacit knowledge level. The formation of cooperative or autonomous governance strategies stems from the specific practices of different countries. Based on the analysis of the literature, it is evident that the United States is a country with a federal 
government where local governments have more power and are less influenced by the dynamics of social operations, which in turn can lead to autonomous dynamics [46-48]. In developed countries such as Europe, where the central government power is more centralized and more influenced by the dynamics of social operations, local governments tend to adopt more cooperative governance strategies [49-51]. In developing countries such as India, Brazil, the Philippines, and Malaysia, government power appears to be centralized but is actually relatively decentralized, with weak governance capacity in both central and local governments in green governance activities [52-55]. On the basis of the above research, this paper uses the Chinese government's green governance experience as a reference to analyze four cohort states formed by focus and non-focus governments based on the combination of governance strategies and the role of pressure fields.

- In the negative-peer state, both parties choose the self-governance strategy. Due to the development ladder, the interaction between the two sides is not strong, while independent governance can retain local characteristics. In this state, both sides' knowledge is only transformed by the internal knowledge chain, and the green development gap is further expanded due to the difference in the knowledge base.

- In the reverse-peer state, the focus government chooses the active leadership strategy, while the non-focus government keeps the independent governance strategy. Due to the high willingness of the focus government, they hope to promote the flow of green governance knowledge and promote green governance of non-focus government. However, due to the lack of initiative and low level of willingness, non-focus governments generally maintain the state of autonomous governance. In this state, the focus government 'follows' the non-focus government's green governance, and the decision-making is in the opposite direction.

- In the positive-peer state, the focus government chooses the active leadership strategy, and the non-focus government chooses the active participation strategy. Because of both sides' complementary ability and willingness, through cooperative governance they can use the knowledge learning effect, knowledge spillover effect, knowledge synergy effect, and knowledge reciprocity effect to improve their abilities or wishes. In this state, the gap of green development is gradually narrowing.

- In the consistent-direction peer status, the focus government chooses the strategy of self-governance, and the non-focus government chooses the strategy of active participation. Because of the low willingness level of some focus governments, they choose independent governance to keep the competitive advantage of the jurisdiction and avoid the risk of cooperation. The non-focus government is willing to seek cooperative governance to realize the internal and external transformation of knowledge. In this state, the non-focus government 'catches up' the focus government's green governance, and the decision-making is in a positive direction. It is worth noting that due to the existence of a basic gap, non-focus government will continue to 'fall behind,' and regional green development differentiation may exist.

The generation of all kinds of green governance peer behavior, the realization of peer behavior adapting to the regional environment, and the generation of peer benefits need knowledge management regulation (as shown in Figure 3). The specific embodiment is as follows: first, the level of green governance ability and willingness of various local governments must be adjusted to make them enter the appropriate group state; secondly, all kinds of the same group state must be guided to the positive-peer state to produce the peer effect. 


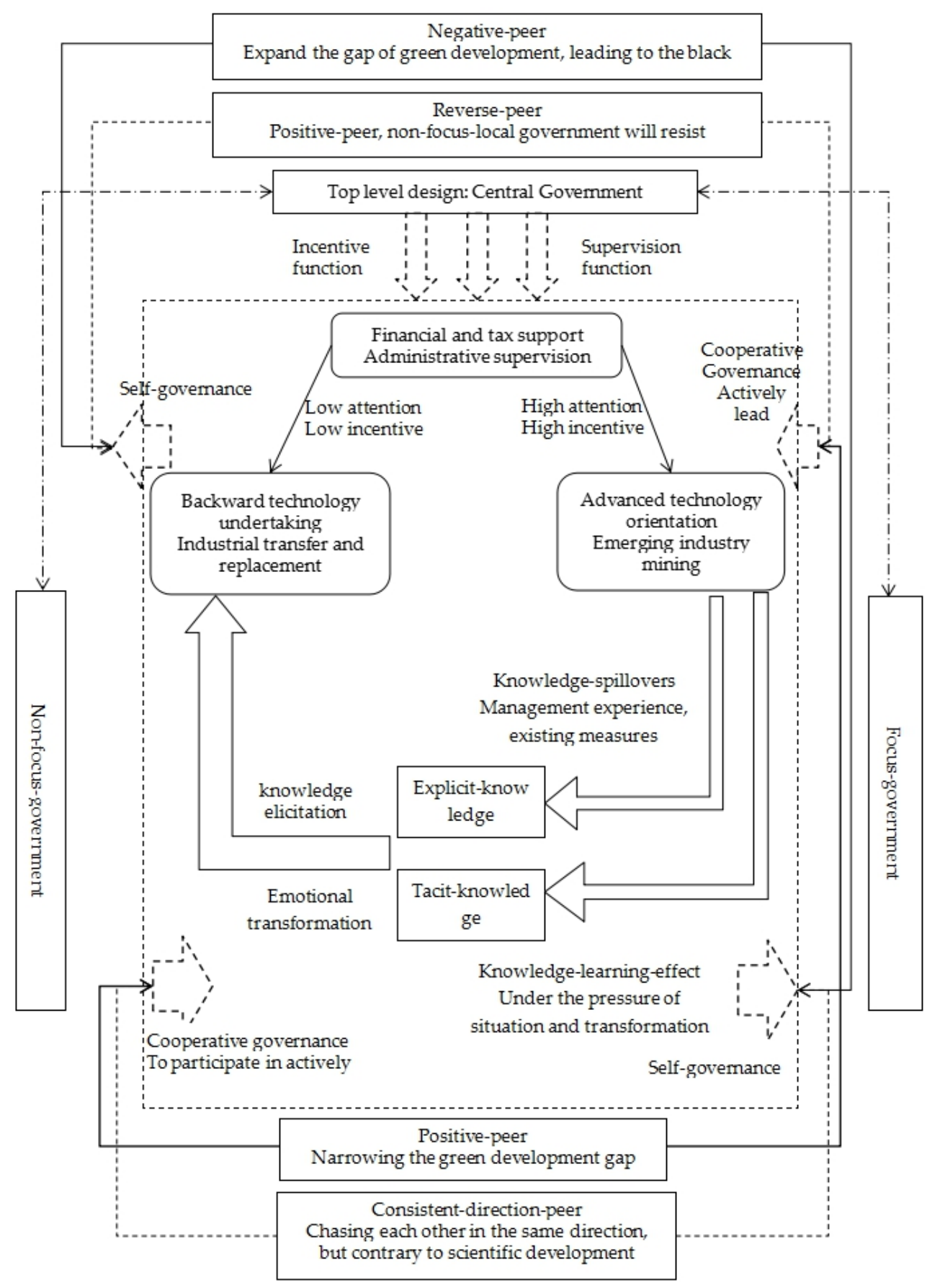

Figure 3. Relationship between green governance and peer behavior.

\section{Evolutionary Game Model of Green Governance Peer Behavior of Local Government}

Under the effect of knowledge management, explicit knowledge, and tacit knowledge, such as green governance ability and willingness, focus governments and non-focus governments are transformed into each other. Because of the interest and the necessity of green governance, the two sides have generated a game relationship of green governance in the collaborative knowledge transformation. Among them, the focus government and non-focus government have two strategies of cooperative governance and autonomous governance, respectively. According to the direction of decision-making and the effect of strategy, they form four conglomeration states: positive-peer (cooperation cooperation), negative-peer (autonomy autonomy), consistent-direction-peer (autonomy cooperation), 
and reverse-peer (cooperation autonomy). As a stable result of the evolutionary game of local government's green governance, peer state is essentially the result of knowledge management regulation on the level of local government's explicit and tacit knowledge. It is also the degree of influence of various knowledge effects on local government's cooperation or autonomous strategy in the stages of internalization of external knowledge, externalization of internal knowledge, and transformation of internal knowledge.

This paper constructs the evolutionary game model and analyzes the ultimate stability strategy of the green governance peer behavior of local government, namely, the final peer state. This paper discusses the influence of each knowledge effect on the stable strategy in each stage of knowledge management and identifies the key factors contributing to the formation of the knowledge effect. On this basis, considering that the goal of knowledge management regulation is the level of explicit and tacit knowledge of local government, the difference of the explicit and tacit knowledge level is related to the same group state. Therefore, numerical evolution and simulation analysis have studied the influence of the local government's explicit and tacit knowledge level on the final peer state. By analyzing the evolutionary stability and the influence of various factors on the peer state, the evolution trend of green governance peer behavior of local government is intuitively displayed and depicted, which provides theoretical guidance for guiding and controlling peer behavior and forming a positive-peer state.

\subsection{Basic Assumptions}

According to the game relationship between the focus government and the non-focus government in green governance, the following assumptions are put forward:

- The focus government adopts two strategies: 'actively leading' or 'autonomous governance'. The probability of choosing 'active leadership' is $x$, and the probability of 'independent governance' is $1-x$. There are two green governance strategies of non-focus government: 'active participation' and 'autonomous governance', the probability of 'active participation' is $y$, and the probability of 'autonomous governance' is $1-y$.

- Both 'social internalization' and 'combinatorial internalization' are the internalization process of external knowledge, and also the process of knowledge appreciation and coordination [56]. The abstract reflection is the influence of the knowledge learning effect and knowledge spillover effect on the behavior of the subject.

a. In the knowledge learning effect, the green governance willingness level (tacit knowledge level) of focus government and non-focus government is $E_{1}$ and $E_{2}$, respectively. The reality is characterized by internal meetings of local governments on green communication, media campaigns on green governance, etc. When they transform knowledge, they are influenced by each other's will. The incentive coefficients of focus government and non-focus government are $a_{1}$ and $a_{2}$, respectively. Indicates the frequency and acceptance of interaction between the parties in reality. Due to the knowledge base gap, non-focus government needs to effectively perceive tacit knowledge in the process of 'learning' from the focus government, so the perception coefficient of the learning effect of non-focus government is set as $c$.

b. In the knowledge spillover effect, the knowledge stock (explicit knowledge level) of green governance of focus government and non-focus government is $K_{1}$ and $K_{2}$, respectively. The reality is characterized by green summary reports and green experiences of local governments. When the two sides interact with each other, they absorb the spillover part of the management experience (government management ability, planning arrangement, etc.) to acquire the other side's knowledge. The knowledge spillover effect among subjects is affected by the proportion of complementary knowledge among subjects, the degree of knowledge protection, the ability of autonomous learning, and the ability of transformation and landing [57]. It is assumed that the proportion of complementary knowledge between focus government and non-focus government is $\alpha_{1}$ and $\alpha_{2}$, the degree of knowledge pro- 
tection is $\beta_{1}$ and $\beta_{2}$, the coefficient of autonomous learning ability is $\lambda_{1}$ and $\lambda_{2}$, and the ability of knowledge transformation is $\theta_{1}$ and $\theta_{2}$.

c. Under the influence of the knowledge learning effect and knowledge spillover effect, focus government and non-focus government construct the knowledge collaborative network of green governance, forming the knowledge collaborative effect. Let $h$ and $i$ be the elasticity coefficients of complementary knowledge stock shared by focus government and non-focus government, respectively, and $h+i=1$. The perceived relationship of trust between the two sides will affect the knowledge synergy effect. The learning effect perception coefficient $c$ reflects the perception relationship. The knowledge synergy effect benefit created by the focus government and the non-focus government is $c\left(\alpha_{1} K_{1}\right)^{h}\left(\alpha_{2} K_{2}\right)^{i}$. In the repeated game of knowledge coordination, the focus government and non-focus government will also be affected by the knowledge reciprocity effect [58]. The open part of the knowledge system realizes the cooperative value added to the original knowledge system through knowledge interaction. Assuming that $\xi$ is the cooperative value-added coefficient, the reciprocal effect of knowledge is inversely proportional to the degree of knowledge protection.

Based on the second hypothesis, we get that the benefits of the knowledge learning effect of the focus government and non-focus government are $E_{2} a_{1}$ and $E_{1}\left(a_{2}+c\right)$, respectively. The return of the knowledge spillover effect income is $K_{2} \alpha_{2}\left(1-\beta_{2}\right) \lambda_{1} K_{1} \theta_{1}$ and $K_{1} \alpha_{1}\left(1-\beta_{1}\right) \lambda_{2} K_{2} \theta_{2}$. Because of the difference of regional foundation and the knowledge synergy effect input, the income of the knowledge synergy effect is not evenly distributed but determined by the proportion of knowledge synergy effect income distribution $z_{1}$ and $z_{2}$. Therefore, the income of the focus government and non-focus government through the knowledge synergy effect is $z_{1} c\left(\alpha_{1} K_{1}\right)^{h}\left(\alpha_{2} K_{2}\right)^{i}$ and $z_{2} c\left(\alpha_{1} K_{1}\right)^{h}\left(\alpha_{2} K_{2}\right)^{i}$, respectively. In the knowledge reciprocity effect, the focus government and non-focus government obtain value-added benefits, which are $K_{1}\left(1-\beta_{1}\right) \xi$ and $K_{2}\left(1-\beta_{2}\right) \xi$, respectively.

- 'Social externalization' and 'combinatorial externalization' are both internal knowledge externalization processes. In the process of knowledge external transfer, each subject has to bear the corresponding expenditure costs, mainly including emotional willingness expenditure, the loss of private value of knowledge, and the use cost of knowledge platform. In the process of social externalized tacit knowledge transfer, there are activity expenses such as collaborative docking and negotiation, assuming that the tacit knowledge expenditure coefficients of focus government and non-focus government are $m_{1}$ and $m_{2}$, respectively. Therefore, the cost of each knowledge learning effect is $m_{1} E_{1}$ and $m_{2} E_{2}$. In the explicit knowledge transfer of combinatorial externalization, the private value of knowledge of all governments is impaired, and the management experience, policy guidance, and other activities need to rely on effective channels or places. The higher the occupation rate of knowledge transformation platform, the higher the cost of human and material resources. Assuming that the value coefficient of explicit knowledge of the focus government and non-focus government is $b_{1}$ and $b_{2}$, respectively, and the occupancy rate of knowledge transformation platform is $d_{1}$ and $d_{2}$, respectively, the cost of the knowledge spillover effect is $K_{1}\left(b_{1}+d_{1}\right)$ and $K_{2}\left(b_{2}+d_{2}\right)$, respectively. In the knowledge synergy effect, in order to build a knowledge collaborative network, the focus government and non-focus government bear the cooperation costs of $n_{1} \alpha_{1} K_{1}$ and $n_{2} \alpha_{2} K_{2}$, respectively, and $n_{1}$ and $n_{2}$ are the respective cooperation cost coefficients.

- In self-governance, knowledge is only transformed internally. At this time, the focus government and non-focus government rely on their own explicit and tacit knowledge to form internal knowledge income $\left(K_{1}+E_{1}\right) R_{1}$ and $\left(K_{2}+E_{2}\right) R_{2}$, where $R_{1}$ and $R_{2}$ are fixed income coefficients. There are differences in the development basis between focus government and non-focus government, and their own governance will further expand the green development gap: $R_{1}>R_{2}$. At the same time, the focus government and the non-focus government rely on the ability of self-learning and knowledge transformation, tap the potential knowledge benefits, and can obtain the knowledge 
value-added benefits of self-governance: $\Delta K_{1} \lambda_{1} \theta_{1}, \Delta K_{2} \lambda_{2} \theta_{2}$, where $\Delta K_{1}, \Delta K_{2}$ are the knowledge increments obtained by both sides through focused learning. Because of the idle spillover knowledge resources and knowledge closure, the focus government and non-focus government will lose the opportunity of spillover knowledge: $K_{1}\left(1-\beta_{1}\right) \gamma_{11}, K_{2}\left(1-\beta_{2}\right) \gamma_{21} \cdot \gamma_{11} \cdot \gamma_{21}$ is the opportunity loss coefficient of the focus government and non-focus government, respectively. The focus government and the non-focus government are punished for the loss of knowledge protection: $K_{1} \beta_{1} \gamma_{12}$ and $K_{2} \beta_{2} \gamma_{22} \cdot \gamma_{12}$ and $\gamma_{22}$ are the penalty coefficients of knowledge protection for the focus government and non-focus government, respectively.

- There are external constraints in knowledge management. When the focus government actively leads and the non-focus government actively participates in green governance, the central government will give corresponding incentive support $R_{g 1}$ and $R_{g 2}$. The central government tries its best to promote the integration of regional green development. When the non-focus government has the will to actively participate and the focus government governs independently, it will give the focus government $F$ punishment. The focus government will eliminate the backward industries to the non-focus government, so the focus government will get the industry elimination income $G_{1}$, and the non-focus government will get the industry transfer income $G_{2}$. Considering the lack of the initial development ability of the non-focus government, when the focus government actively leads and the non-focus government governs independently, the central government will not punish the non-focus government temporarily. Any party who refuses to cooperate in governance will suffer credit loss $T$.

\subsection{Payment Matrix and Dynamic Equation of Replication}

When the focus government and non-focus government are positive peers, the corresponding strategy combination is active leadership and active participation. Each subject realizes the internal and external transformation of knowledge, keeps the internal knowledge benefits, and undertakes the cost of the knowledge learning effect, knowledge spillover effect and knowledge spillover effect. Each subject obtains the benefits of the knowledge learning effect, knowledge spillover effect, knowledge synergy effect, knowledge reciprocity effect, and the incentive support given by the central government. In the case of negative peers corresponding to the combination of strategies of autonomous governance and autonomous governance, knowledge only transforms internally. Each subject undertakes the opportunity to lose spillover knowledge and the penalty loss of knowledge protection, gains internal knowledge benefits, and gains value-added benefits through self-governance. In the case of consistent direction peers, the strategy combination is autonomous governance and active participation. The focus government bears the loss of knowledge opportunity and knowledge protection punishment and suffers from external punishment and reputation loss, but gains internal knowledge income, value-added income, and industry elimination income. At this time, the non-focus government bears the cost of the knowledge learning effect and knowledge spillover effect. Because the cooperative relationship cannot be constructed, it can only obtain internal knowledge benefits, industrial transfer benefits, and the central government's incentive. In the case of reverse peers, the corresponding strategy combination is active leadership and autonomous governance. The focus government bears the cost of knowledge learning and spillover. Because of the blocking of knowledge transformation, they only gain internal knowledge benefits and incentive benefits. The non-focus government loses the knowledge opportunity income and bears the punishment of knowledge protection and faces the reputation loss but gains the internal knowledge income and value-added income.

According to the above assumptions and the profit and loss analysis, the payment matrix of the game is obtained, as shown in Table 1. 
Table 1. Payment matrix of the game between the Non-focus government and non-focus government.

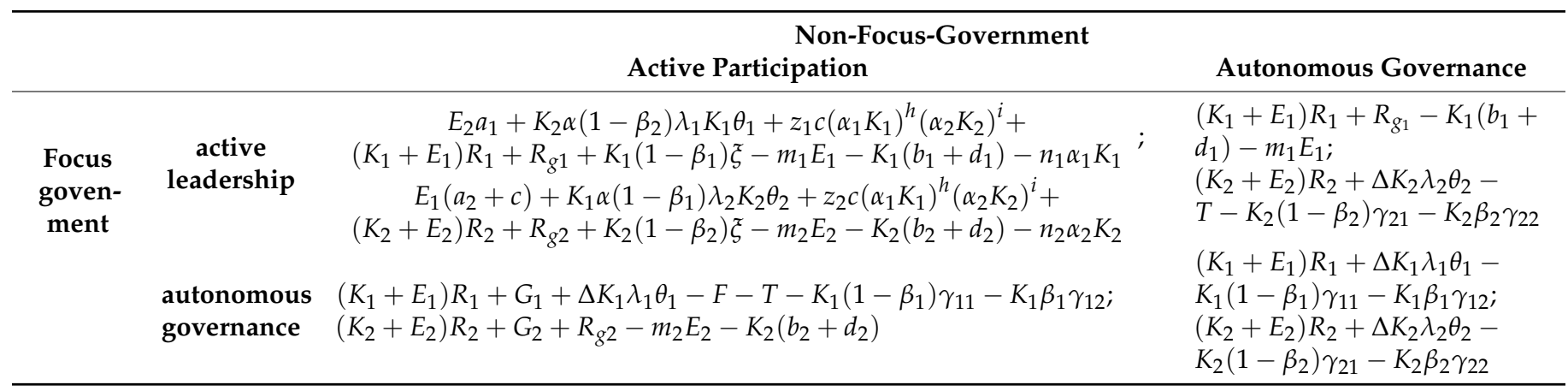

According to the revenue matrix in Table 1, we can calculate the expected revenue and average revenue when the focus government and non-focus government choose different strategies. The expected benefits of active leadership $U_{11}$, autonomous governance $U_{12}$, and average income $U_{1}$ of the focus government can be expressed as:

$$
\begin{gathered}
\begin{array}{c}
U_{11}=y\left[E_{2} a_{1}+K_{2} \alpha\left(1-\beta_{2}\right) \lambda_{1} K_{1} \theta_{1}+z_{1} c\left(\alpha_{1} K_{1}\right)^{h}\left(\alpha_{2} K_{2}\right)^{i}+\left(K_{1}+E_{1}\right) R_{1}+R_{g 1}+K_{1}\left(1-\beta_{1}\right) \xi-m_{1} E_{1}-K_{1}\left(b_{1}+d_{1}\right)-n_{1} \alpha_{1} K_{1}\right] \\
+(1-y)\left[\left(K_{1}+E_{1}\right) R_{1}+R_{g 1}-K_{1}\left(b_{1}+d_{1}\right)-m_{1} E_{1}\right]
\end{array} \\
\begin{array}{c}
U_{12}=y\left[\left(K_{1}+E_{1}\right) R_{1}+G_{1}+\Delta K_{1} \lambda_{1} \theta_{1}-F-T-K_{1}\left(1-\beta_{1}\right) \gamma_{11}-K_{1} \beta_{1} \gamma_{12}\right]+(1-y)\left[\left(K_{1}+E_{1}\right) R_{1}+\Delta K_{1} \lambda_{1} \theta_{1}-K_{1}\left(1-\beta_{1}\right) \gamma_{11}-K_{1} \beta_{1} \gamma_{12}\right] \\
U_{1}=x U_{11}+(1-x) U_{12}
\end{array}
\end{gathered}
$$

Similarly, the expected benefits of non-focus government $U_{21}$ (active participation), $U_{22}$ (autonomous governance), and $U_{2}$ (average benefits) can be expressed as follows

$$
\begin{gathered}
U_{21}=x\left[E_{1}\left(a_{2}+c\right)+K_{1} \alpha\left(1-\beta_{1}\right) \lambda_{2} K_{2} \theta_{2}+z_{2} c\left(\alpha_{1} K_{1}\right)^{h}\left(\alpha_{2} K_{2}\right)^{i}+\left(K_{2}+E_{2}\right) R_{2}+R_{g^{2}}+K_{2}\left(1-\beta_{2}\right) \xi-m_{2} E_{2}-K_{2}\left(b_{2}+d_{2}\right)-n_{2} \alpha_{2} K_{2}\right] \\
+(1-x)\left[\left(K_{2}+E_{2}\right) R_{2}+G_{2}+R_{g 2}-K_{2}\left(b_{2}+d_{2}\right)-m_{2} E_{2}\right] \\
\begin{array}{c}
U_{22}=x\left[\left(K_{2}+E_{2}\right) R_{2}+\Delta K_{2} \lambda_{2} \theta_{2}-T-K_{2}\left(1-\beta_{2}\right) \gamma_{21}-K_{2} \beta_{2} \gamma_{22}\right]+(1-x)\left[\left(K_{2}+E_{2}\right) R_{2}+\Delta K_{2} \lambda_{2} \theta_{2}-K_{2}\left(1-\beta_{2}\right) \gamma_{21}-K_{2} \beta_{2} \gamma_{22}\right] \\
U_{2}=y U_{21}+(1-y) U_{22}
\end{array}
\end{gathered}
$$

From the above expressions, the replication dynamic equations of the focus government and non-focus government can be calculated.

The dynamic replication equation of the focus government's choice of active leadership strategy is as follows:

$$
\begin{array}{cc}
F(x)=\frac{d x}{d t}=\quad & x\left(U_{11}-U_{1}\right)=x(1-x)\left\{y \left[E_{2} a_{1}+K_{2} \alpha_{2}\left(1-\beta_{2}\right) \lambda_{1} K_{1} \theta_{1}+z_{1} c\left(\alpha_{1} K_{1}\right)^{h}\left(\alpha_{2} K_{2}\right)^{i}+K_{1}\left(1-\beta_{1}\right) \xi\right.\right. \\
& \left.\left.-n_{1} \alpha_{1} K_{1}-G_{1}+F+T\right]+\left[R_{g 1}-K_{1}\left(b_{1}+d_{1}\right)-m_{1} E_{1}-\Delta K_{1} \lambda_{1} \theta_{1}+K_{1}\left(1-\beta_{1}\right) \gamma_{11}+K_{1} \beta_{1} \gamma_{12}\right]\right\}
\end{array}
$$

The dynamic replication equation of the non-focus government's choice of active participation strategy is as follows:

$$
\begin{aligned}
F(y)=\frac{d y}{d t}= & y\left(U_{21}-U_{2}\right)=y(1-y)\left\{x \left[E_{1}\left(a_{2}+c\right)+K_{1} \alpha_{1}\left(1-\beta_{1}\right) \lambda_{2} K_{2} \theta_{2}+z_{2} c\left(\alpha_{1} K_{1}\right)^{h}\left(\alpha_{2} K_{2}\right)^{i}+K_{2}\left(1-\beta_{2}\right) \xi\right.\right. \\
& \left.\left.-n_{2} \alpha_{2} K_{2}-G_{2}+T\right]+\left[R_{g 2}+G_{2}-K_{2}\left(b_{2}+d_{2}\right)-m_{2} E_{2}-\Delta K_{2} \lambda_{2} \theta_{2}+K_{2}\left(1-\beta_{2}\right) \gamma_{21}+K_{2} \beta_{2} \gamma_{22}\right]\right\}
\end{aligned}
$$

In order to solve the equilibrium point-of-evolution game, let $F(x)=0$ and $F(y)=0$, five local equilibrium points can be obtained: a $(0,0), \mathrm{B}(0,1), \mathrm{C}(1,0), \mathrm{D}(1,1)$ and $\mathrm{E}\left(x^{*}, y^{*}\right)$. Where $x^{*}, y^{*}$ are:

$$
x^{*}=\frac{K_{2}\left(b_{2}+d_{2}\right)+m_{2} E_{2}+\Delta K_{2} \lambda_{2} \theta_{2}-R_{g 2}-G_{2}-K_{2}\left(1-\beta_{2}\right) \gamma_{21}-K_{2} \beta_{2} \gamma_{22}}{E_{1}\left(a_{2}+c\right)+K_{1} \alpha_{1}\left(1-\beta_{1}\right) \lambda_{2} K_{2} \theta_{2}+z_{2} c\left(\alpha_{1} K_{1}\right)^{h}\left(\alpha_{2} K_{2}\right)^{i}+K_{2}\left(1-\beta_{2}\right) \xi-n_{2} \alpha_{2} K_{2}-G_{2}+T}
$$




$$
y^{*}=\frac{K_{1}\left(b_{1}+d_{1}\right)+m_{1} E_{1}+\Delta K_{1} \lambda_{1} \theta_{1}-R_{g 1}-K_{1}\left(1-\beta_{1}\right) \gamma_{11}-K_{1} \beta_{1} \gamma_{12}}{E_{2} a_{1}+K_{2} \alpha_{2}\left(1-\beta_{2}\right) \lambda_{1} K_{1} \theta_{1}+z_{1} c\left(\alpha_{1} K_{1}\right)^{h}\left(\alpha_{2} K_{2}\right)^{i}+K_{1}\left(1-\beta_{1}\right) \xi-n_{1} \alpha_{1} K_{1}-G_{1}+F+T}
$$

\subsection{Equilibrium Stability Strategy Analysis}

According to Hirshleifer theory [59], the Jacobian matrix can be used to analyze the local stability of the evolutionary system at the above five equilibrium points. According to the dynamic replication equation, the Jacobian matrix is obtained.

$$
J=\left[\begin{array}{l}
\frac{\partial F(x)}{\partial(x)} \frac{\partial F(x)}{\partial(y)} \\
\frac{\partial F(y)}{\partial(x)} \frac{\partial F(y)}{\partial(y)}
\end{array}\right]=\left[\begin{array}{l}
A B \\
C D
\end{array}\right]
$$

Among them,

$$
\begin{aligned}
A= & (1-2 x)\left\{y \left[E_{2} a_{1}+K_{2} \alpha_{2}\left(1-\beta_{2}\right) \lambda_{1} K_{1} \theta_{1}+z_{1} c\left(\alpha_{1} K_{1}\right)^{h}\left(\alpha_{2} K_{2}\right)^{i}+K_{1}\left(1-\beta_{1}\right) \xi\right.\right. \\
& \left.\left.-n_{1} \alpha_{1} K_{1}-G_{1}+F+T\right]+\left[R_{g 1}-K_{1}\left(b_{1}+d_{1}\right)-m_{1} E_{1}-\Delta K_{1} \lambda_{1} \theta_{1}+K_{1}\left(1-\beta_{1}\right) \gamma_{11}+K_{1} \beta_{1} \gamma_{12}\right]\right\} \\
B= & x(1-x)\left[E_{2} a_{1}+K_{2} \alpha_{2}\left(1-\beta_{2}\right) \lambda_{1} K_{1} \theta_{1}+z_{1} c\left(\alpha_{1} K_{1}\right)^{h}\left(\alpha_{2} K_{2}\right)^{i}+K_{1}\left(1-\beta_{1}\right) \xi-n_{1} \alpha_{1} K_{1}-G_{1}+F+T\right] \\
C=y & (1-y)\left[E_{1}\left(a_{2}+c\right)+K_{1} \alpha_{1}\left(1-\beta_{1}\right) \lambda_{2} K_{2} \theta_{2}+z_{2} c\left(\alpha_{1} K_{1}\right)^{h}\left(\alpha_{2} K_{2}\right)^{i}+K_{2}\left(1-\beta_{2}\right) \xi-n_{2} \alpha_{2} K_{2}-G_{2}+T\right] \\
D= & (1-2 y)\left\{x \left[E_{1}\left(a_{2}+c\right)+K_{1} \alpha_{1}\left(1-\beta_{1}\right) \lambda_{2} K_{2} \theta_{2}+z_{2} c\left(\alpha_{1} K_{1}\right)^{h}\left(\alpha_{2} K_{2}\right)^{i}+K_{2}\left(1-\beta_{2}\right) \xi\right.\right. \\
& \left.\left.-n_{2} \alpha_{2} K_{2}-G_{2}+T\right]+\left[R_{g 2}+G_{2}-K_{2}\left(b_{2}+d_{2}\right)-m_{2} E_{2}-\Delta K_{2} \lambda_{2} \theta_{2}+K_{2}\left(1-\beta_{2}\right) \gamma_{21}+K_{2} \beta_{2} \gamma_{22}\right]\right\}
\end{aligned}
$$

Then the trace of the matrix is: $\operatorname{tr} J=A+D$.

The determinant of the Jacobian matrix and the sign of trace can determine when the above five equilibrium points are stable strategies (ESS). When $\operatorname{tr} J<0$ and $\operatorname{det} J=|J|>0$ are satisfied, the equilibrium point reaches a stable state and finally becomes a stable strategy.

Because $x^{*}, y^{*} \in[0,1]$, we get

$$
\begin{gathered}
K_{1}\left(b_{1}+d_{1}\right)+m_{1} E_{1}+\Delta K_{1} \lambda_{1} \theta_{1}-R_{g 1}-K_{1}\left(1-\beta_{1}\right) \gamma_{11}-K_{1} \beta_{1} \gamma_{12}>0 \\
K_{2}\left(b_{2}+d_{2}\right)+m_{2} E_{2}+\Delta K_{2} \lambda_{2} \theta_{2}-R_{g 2}-G_{2}-K_{2}\left(1-\beta_{2}\right) \gamma_{21}-K_{1} \beta_{1} \gamma_{22}>0
\end{gathered}
$$

That is, when both sides choose to govern independently, the benefits are greater than those of one party seeking cooperation with the other. It shows that if the two sides cannot reach a cooperation agreement, the active participants will suffer a great loss. The overall benefit of the consistent direction peers or reverse peers is less than that of negative peers. Under this condition, the local stability results of the five equilibrium points are shown in Table 2.

Table 2. Local stability analysis of equilibrium point.

\begin{tabular}{cccc}
\hline Equilibrium Points & trJ & det $J$ & Local Stability \\
\hline A $(0,0)$ & - & + & ESS \\
B $(0,1)$ & + & + & Instable \\
C $(1,0)$ & + & + & Instable \\
D $(1,1)$ & - & + & ESS \\
E $\left(x^{*}, y^{*}\right)$ & $/$ & 0 & Saddle point \\
\hline
\end{tabular}

It can be seen from Table 2 that there are two unstable points $B(0,1)$ and $C(1,0)$ in the evolution system of green governance peer behavior of the focus government and non-focus government. Point $\mathrm{E}\left(x^{*}, y^{*}\right)$ is the saddle point and point $\mathrm{A}(0,0)$ and point $\mathrm{D}(1,1)$ are the stable points of the system. Therefore, the evolution phase diagram of the system is shown in Figure 4. 


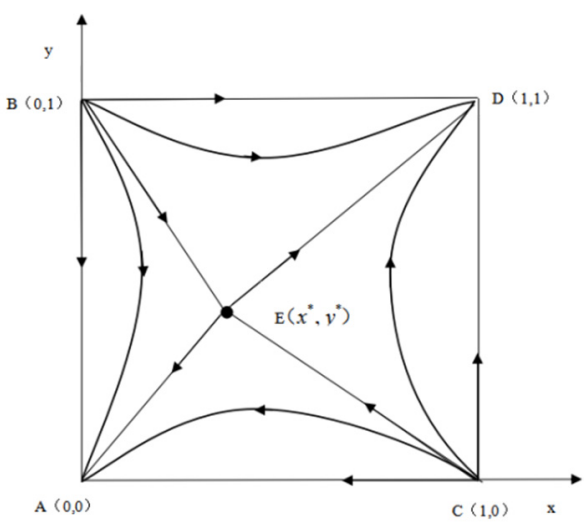

Figure 4. Phase diagram of system evolution.

It can be seen from Figure 4 that the saddle point position determines the stable strategy and the final partner state of the focus government and the non-focus government. Taking the broken line connected by points $\mathrm{B}, \mathrm{C}$, and $\mathrm{E}$ as the convergence critical line of the system, at the top right of the broken line (BECD) the system converges to the positive-peer state. In the lower left part of the broken line (ABEC part), the system converges to the negative-peer state. The larger the area of convergence region (BECD or ABEC), the closer the system is to the stable point (points D, A).

\subsection{Influence of Knowledge Management on the Evolution Trend of Peer Behavior}

4.4.1. The Evolution Trend of Peer Behavior in the Internalization Stage of External Knowledge

From the expressions of $x^{*}$ and $y^{*}$, we can see that:

- The effect of knowledge learning promotes the focus government and non-focus government to actively participate in knowledge transformation activities to achieve a positive-peer state. Willingness stimulus coefficient $a_{1}, a_{2}$ and learning effect perception coefficient $c$ are the decreasing functions of $x^{*}$ and $y^{*}$. With the higher stimulation degree of the two kinds of government to the knowledge learning effect, the stronger the relationship between perception and trust. Saddle point e gradually transfers to equilibrium point $A$, and the system is stable in the positive-peer state of active leadership and active participation.

- The knowledge synergy effect plays a positive role in promoting the focus government and non-focus government to achieve positive-peer status. With the increase of elasticity coefficient, $h, i$ of complementary knowledge stock and distribution ratio $z_{1}, z_{2}$ of knowledge synergy income, BECD area increases significantly. This shows that the higher the elasticity of complementary knowledge stock of focus government and non-focus government, the higher the income of the knowledge synergy effect transformation, which is greater than the income of their own governance and promotes both sides of the game to stay in a positive-peer state. At the same time, the higher the distribution coefficient of synergy benefits, the stronger their willingness to participate, but it is possible for both sides to fall into a bad situation of competing for interests. Because the elasticity coefficient of complementary knowledge stock has a relationship of $h+i=1$ and the focus government knowledge stock is significantly higher than that of non-focus government, the complementary knowledge stock elasticity coefficient of the focus government has a stronger effect on the overall knowledge synergy effect income.

- The reciprocal effect of knowledge promotes the evolutionary system to a positive-peer state. The cooperative value-added coefficient $\xi$ is decreasing with $x^{*}$ and $y^{*}$, which indicates that under the knowledge collaborative network, the focus government and non-focus government gain value-added benefits, and the system will converge to a stable state of active leadership and active participation. 
Conclusion 1: The stronger the trust relationship between the two types of governments, the closer the exchange of management will be, and the knowledge learning effect will promote the two sides to enter into a positive-peer state. The two types of government should intensify the frequency of communication, actively align their willingness to green governance and strengthen the positive-peer effects.

Conclusion 2: In the process of knowledge synergy, if the two types of government knowledge structure are complementary and the non-focus government is willing to give part of the synergy benefits to the focus government, this will contribute to the stability of the positive-peer state of both sides. At this point, non-focal governments should focus on the long-term benefits of green governance and avoid short-term horizons that limit the positive-peer effects.

Conclusion 3: If the ability of knowledge cooperation and development is strong, it will obtain a higher knowledge reciprocity effect to maintain a positive-peer state. Therefore, the two types of governments should dovetail their spatial governance policies to jointly promote green industry development to avoid the excessive losses of a single development.

\subsubsection{Evolution Trend of Peer Behavior in Internal Knowledge Externalization Stage}

From the expressions of $x^{*}$ and $y^{*}$, we can see that:

- The input cost of the knowledge learning effect suppresses the participation enthusiasm of the focus government and non-focus government. Tacit knowledge expenditure coefficients $m_{1}$ and $m_{2}$ are increasing functions of $x^{*}$ and $y^{*}$. With the increase of parameter value, saddle point e gradually approaches equilibrium point $D$, and the $A B E C$ region expands continuously. The system converges to the negative-peer state of autonomous governance and autonomous governance.

- The knowledge protection behavior and cost input in the knowledge spillover effect have negative effects on the evolution system. The degree of knowledge protection $\beta_{1}$, $\beta_{2}$, the value coefficient of explicit knowledge $b_{1}, b_{2}$, the occupation rate of knowledge transformation platform $d_{1}, d_{2}$ and $x^{*}, y^{*}$ showed an increasing relationship. With the increase of parameter value, the ABEC region increased significantly. This shows that the increase of the value coefficient of explicit knowledge leads to the two kinds of governments paying more attention to the protection of knowledge. On the one hand, it increases the cost of knowledge spillover, on the other hand, it reduces the knowledge that can be shared and used, which makes both sides more likely to self-governance. At the same time, due to the increase of the occupation rate of the knowledge transformation platform, the load of knowledge transformation increases and the efficiency of knowledge spillover decreases, which is not conducive to the construction of a knowledge collaboration network.

Conclusion 4: The higher the cost of the tacit knowledge exchange between the two types of government, the weaker the knowledge learning effect acquired by both sides, which leads to a negative-peer state for both sides.

Conclusion 5: The higher degree of protection for the two types of government will lead to higher value knowledge and the overcrowding of the knowledge transformation platform will lead to the closure of knowledge activities, which will make it difficult for both sides to obtain the knowledge spillover effect. This tends to lead to a negative-peer state.

\subsubsection{Peer Behavior Evolution Trend in Internal Knowledge Transformation Stage}

From the expressions of $x^{*}$ and $y^{*}$, we can see that:

- The increment of autonomous governance knowledge $\Delta K_{1}$ and $\Delta K_{2}$ are positively correlated with $x^{*}$ and $y^{*}$. With the increase of parameter value, the system converges to the negative-peer state. This shows that when the two players choose the selfgovernance strategy, the value-added benefits brought by self-focused development are higher than that of knowledge collaborative transformation, so they tend to choose the negative-peer state. There is no doubt that in this development mode, 
both focus government and non-focus government can construct a green governance mode with local characteristics and expand the stock of government knowledge. However, due to the weak foundation of non-focus government, the knowledge increment of the two is obviously not at the same level, which leads to the further widening of the development gap. This is also the 'negativity' of the negative-peer state. From the perspective of revenue, the knowledge incremental revenue of both sides is obviously greater than the knowledge synergy effect revenue in the short term. Because the latter needs continuous investment and stable knowledge exchange channels (low knowledge protection, low platform occupancy rate, etc.), the two types of governments tend to choose autonomous governance.

- The chance loss coefficient $\gamma_{11}, \gamma_{21}$ and knowledge protection penalty coefficient $\gamma_{12}$, $\gamma_{22}$ are negatively correlated with $x^{*}, y^{*}$. With the increase of the parameter value, the system converges to a positive-peer state. The higher the value of knowledge opportunity utilization and the greater the punishment to knowledge protection forces both sides to choose the actively lead and actively participate strategy. As a rational decision, when one party is idle or the redundant knowledge is too much, the other party needs corresponding knowledge to make up for it. The knowledge collaborative transformation activity can not only enlarge the value of knowledge, but also reduce punishment by opening knowledge and promoting the green collaborative development of the region.

Conclusion 6: The stronger the ability of the two kinds of governments to mine their own knowledge, the lower their willingness to participate in knowledge interaction, which leads to the formation of a negative-peer state.

Conclusion 7: The increase of opportunity and income of knowledge will enhance the willingness of the two types of government to participate in knowledge interaction. The increase of knowledge protection punishment will further promote the formation of a positive-peer state.

4.4.4. Influence of External Constraints of Knowledge Management on the Evolutionary Trend of Behavior of the Peer

From the expressions of $x^{*}$ and $y^{*}$, we can see that the loss of credit $T$ and punishment $F$ are decreasing functions of $x^{*}$ and $y^{*}$. When the value of $T$ or $F$ is increased, saddle point $\mathrm{E}$ tends to be stable point $\mathrm{A}$. This shows that the greater the loss of government image or reputation, the more the government external expenditure caused by breach of contract and the resulting loss makes the organization tend to choose positive behavior. Considering that the central government is not willing to lead the focus government, the greater the exit penalty of the focus government is, the more the focus government will choose to actively lead. Therefore, in the consistent direction peer, punishment $F$ suppresses the formation of the consistent-direction-peer state, while reputation loss $T$ promotes the non-focus government to expand internal expenditure, avoid the occurrence of the adverse peer state, and finally guide both sides of the game to stabilize in the positive-peer state.

Conclusion 8: Stronger punishment and stronger binding forces of the intergovernmental cooperation contract will promote the two types of governments to maintain a positive-peer state.

\subsection{The Influence of Explicit and Tacit Knowledge Level on the Final Peer State}

In order to investigate the influence of explicit and tacit knowledge level of the focus government and non-focus government on knowledge transformation behavior and final peer state more intuitively, this paper used MATLAB to carry out numerical simulation. The initial parameter assignment is shown in Table 3 , and the initial behavior probability was set as $(0.5,0.5)$. In this regard, the initial data were modelled and selected from government reports on the Yangtze River Economic Zone, and the corresponding indicators that could be drawn upon were transformed to the same order of magnitude. For example, K1 is the average number of green governance policies made public by the three focus governments 
of Jiangsu, Zhejiang, and Shanghai over the years, while K2 is the average number of green governance policies of non-focus governments such as Anhui. Other indicators were similarly compared to ensure the validity of the simulation.

Table 3. Initial parameter assignment.

\begin{tabular}{|c|c|c|c|c|c|c|c|}
\hline $\begin{array}{c}\text { Related } \\
\text { Parameters }\end{array}$ & $\begin{array}{l}\text { Parameter } \\
\text { Value }\end{array}$ & $\begin{array}{c}\text { Related } \\
\text { Parameters }\end{array}$ & $\begin{array}{l}\text { Parameter } \\
\text { Value }\end{array}$ & $\begin{array}{c}\text { Related } \\
\text { Parameters }\end{array}$ & $\begin{array}{l}\text { Parameter } \\
\text { Value }\end{array}$ & $\begin{array}{c}\text { Related } \\
\text { Parameters }\end{array}$ & $\begin{array}{c}\text { Parameter } \\
\text { Value }\end{array}$ \\
\hline$K_{1}$ & 5 & $K_{2}$ & 4 & $E_{1}$ & 5 & $E_{2}$ & 4 \\
\hline$a_{1}$ & 0.5 & $a_{2}$ & 0.8 & $b_{1}$ & 2.4 & $b_{2}$ & 2 \\
\hline$d_{1}$ & 0.6 & $d_{2}$ & 0.5 & $F$ & 0.2 & $G_{1}$ & 5 \\
\hline$G_{2}$ & 1 & $h$ & 0.5 & $i$ & 0.5 & c & 0.5 \\
\hline$m_{1}$ & 0.6 & $m_{2}$ & 0.5 & $n_{1}$ & 3 & $n_{2}$ & 2 \\
\hline$R_{g 1}$ & 0.2 & $R_{g 2}$ & 1 & $T$ & 1.8 & $z_{1}$ & 0.6 \\
\hline$z_{2}$ & 0.4 & $\Delta K_{1}$ & 3 & $\Delta K_{2}$ & 2 & $\alpha_{1}$ & 0.4 \\
\hline$\alpha_{2}$ & 0.6 & $\beta_{1}$ & 0.8 & $\beta_{2}$ & 0.5 & $\lambda_{1}$ & 0.6 \\
\hline$\lambda_{2}$ & 0.5 & $\theta_{1}$ & 0.6 & $\theta_{2}$ & 0.5 & $\gamma_{11}$ & 3 \\
\hline$\gamma_{21}$ & 2 & $\gamma_{12}$ & 2 & $\gamma_{22}$ & 1 & $\xi$ & 5 \\
\hline
\end{tabular}

The effect of the willingness level of green governance (tacit knowledge level) on peer status was analyzed. With other parameters unchanged, it can be seen from Figure 5 that:

- (1) In Figure 5a, when the tacit knowledge level of the focus government and nonfocus government is low as a whole $(E<10)$, both sides eventually tend to be in a negative-peer state $(0,0)$. Among them, the non-focus government's willingness to actively participate will first have a small increase, and with the evolution of time, the willingness to participate will decline. The willingness of the focus government to actively lead will first decline significantly, then decline steadily and stay in the state of self-governance. Therefore, both sides experience the evolution process from consistent direction peer to negative peer. (2) When $E_{2}$ is constant and $E_{1}$ is higher, the speed of non-focus government converging to the state of self-governance slows down but accelerates the decline of focus government's willingness to actively lead. When $E_{1}$ remains unchanged and $E_{2}$ is lower, the willingness of non-focus government to actively participate is stronger, and the decline speed of willingness further slows down and the convergence speed of focus government to self-governance is also slower than that of the higher $E_{1}$ state. (3) In the early stage of knowledge transformation, the benefit of the non-focus government's knowledge learning effect is greater than the expenditure of knowledge externalization, so its willingness to actively participate has increased. The larger the knowledge gap and the lower the level of tacit knowledge, the lower the decline rate of willingness to participate. For the focus government, the higher the level of tacit knowledge, the higher the cost of knowledge externalization and the faster the decline of participation willingness. The increase of the knowledge gap further enlarges the imbalance of the focus government, which leads to its choice of independent governance strategy.

- In Figure 5b, (1) when the tacit knowledge level of the focus government and non-focus government is higher as a whole $(E>20)$ or the tacit knowledge gap is larger, both sides tend to be in a negative-peer state $(0,0)$. Different from the feedback in Figure $5 a$, when the level of tacit knowledge is high, the willingness of active participation of the focus government and non-focus government rapidly declines and the speed of convergence to a negative-peer state $(0,0)$ accelerates, and there is no transition period of a consistent-direction-peer state. (2) As the tacit knowledge level of the non-focus government is higher than that of the focus government, the willingness of the non-focus government to actively participate in the decline is faster, while the decline rate of the focus government is slower. (3) When the level of tacit knowledge on both sides is high, the benefits of learning and imitation will narrow. When the 
knowledge gap increases significantly, the positive will of the focus government and the non-focus government will first increase slightly.

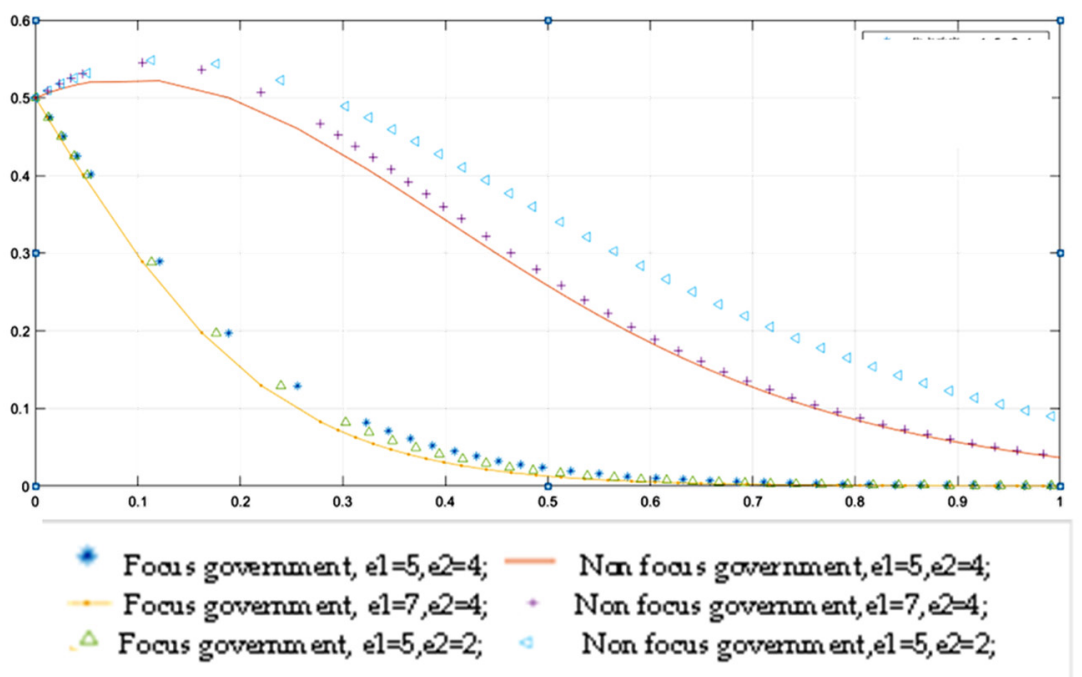

(a) $\mathrm{E}<20$

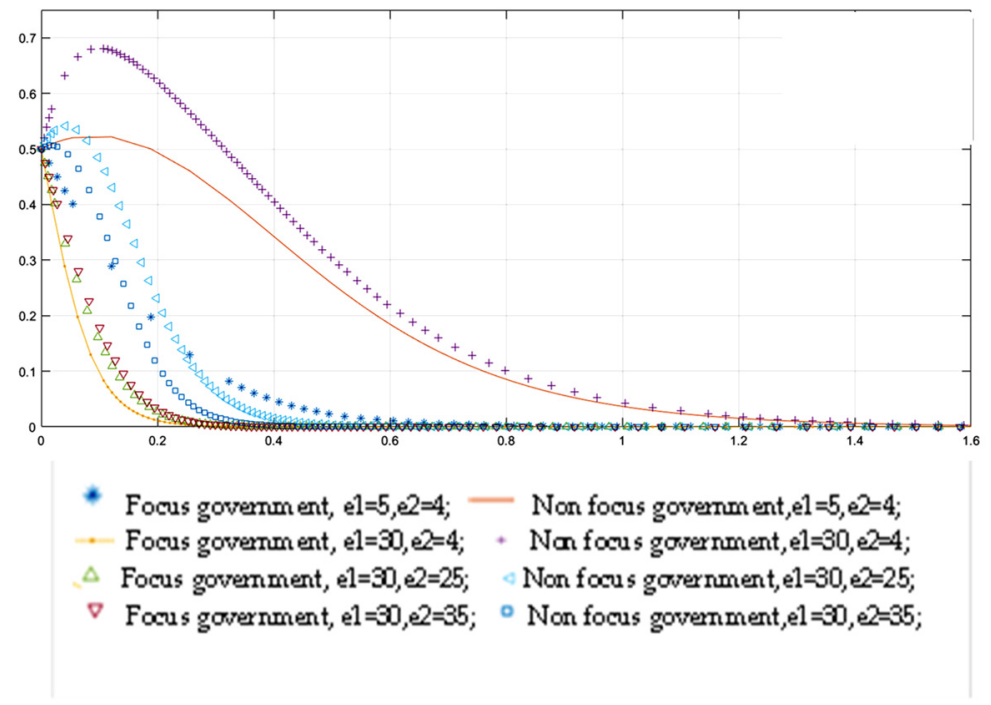

(b) $\mathrm{E}>20$

Figure 5. Evolution of the same peer state of both sides of the game when the tacit knowledge level changes.

The effect of knowledge stock (explicit knowledge level) of green governance on peer status was analyzed. With other parameters unchanged, it can be seen from Figure 6:

- In Figure 6a, (1) when the explicit knowledge level of focus government and non-focus government is low as a whole $(K<10)$, both sides eventually tend to be in a negativepeer state $(0,0)$. Among them, the willingness of non-focus governments to actively participate increases slightly at first and then decreases slowly. The focus government's willingness to actively lead continues to decline, and the decline rate gradually slows down. Similar to the mechanism of tacit knowledge, with the increase of knowledge, the focus government's willingness to lead decreases and increases rapidly, and the expansion of the knowledge gap also leads to the decline of leadership intention. However, the willingness of non-focus government to participate in the process of change is different. When the knowledge gap is large, the willingness of non-focus 
government to participate in the process of change is low. (2) With the decrease of their explicit knowledge level, the willingness curve of active participation rises. However, when the knowledge gap expands, the role of the knowledge spillover effect on nonfocus government is reduced, and it is difficult for non-focus government with a weak foundation to obtain favorable resources and generate substantial benefits through the knowledge spillover effect. In the background there are external investments but as profits and the focus government's active will are not strong, the non-focus government tends to finally move to autonomous governance mode. It can be seen that the knowledge gap limits the role of the knowledge spillover effect, leading to a negative-peer state of the system.

- In Figure 6b, (1) when the explicit knowledge level of the focus government and non-focus government is higher as a whole $(K>20)$ or the explicit knowledge gap changes, the final state of both side changes. With the obvious increase of the explicit knowledge gap, the positive will of both sides continues to decrease, which is faster than that in Figure 6a. This reflects the existing problems of regional green development: In order to build better and faster in the green advantage industry and give play to the 'first mover' advantage, the focus government will speed up the pace of independent development, leading to the widening gap of explicit knowledge, such as the management experience of local governments among regions. (2) When both sides are in a state of a high level of explicit knowledge, the benefit of the knowledge spillover effect is significantly higher than that of external expenditure. At this time, although the focus government undertakes more external investment due to the rise of the stock of non-focus government knowledge, the focus government can also accept part of the spillover knowledge and make up for its own shortcomings. The two sides present the collaborative situation of mutual benefits and a win-win relationship, forming a $(1,1)$ positive-peer state.

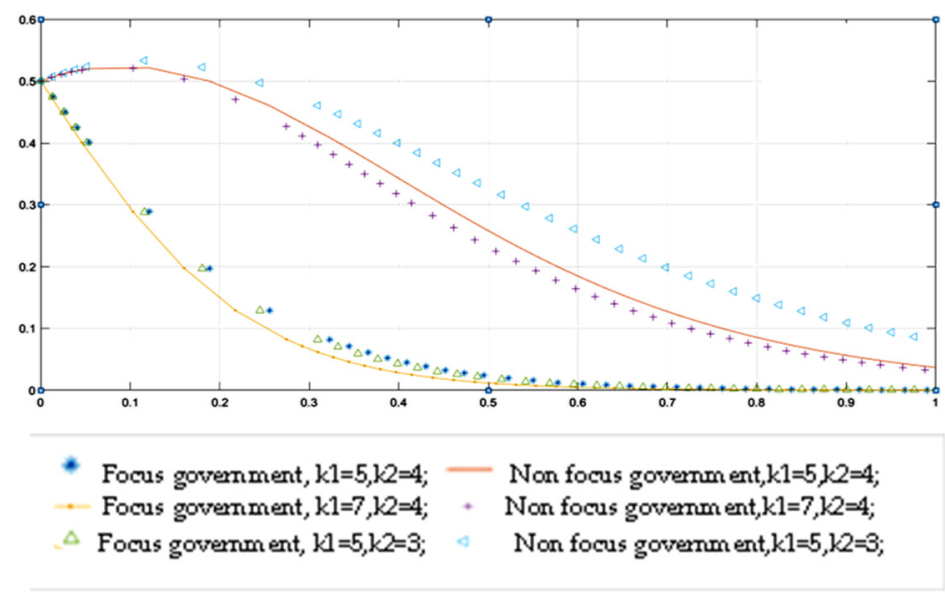

(a) $\mathrm{K}<20$

Figure 6. Cont. 


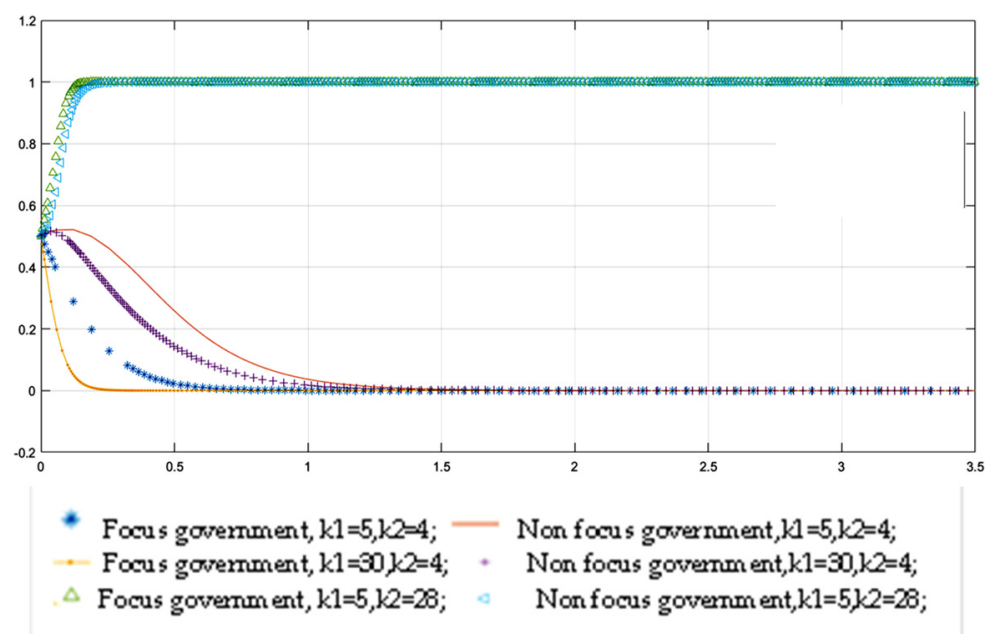

(b) $\mathrm{K}>20$

Figure 6. Evolution of the same peer state of both sides of the game when the level of explicit knowledge changes.

\section{Conclusions and Suggestions}

Based on the improved SECI model, this paper constructs a dynamic evolutionary game model of local government green governance peer behavior and further explains the mechanism of knowledge management on local government green governance peer behavior. It also considers the effects of knowledge learning, knowledge spillover, knowledge synergy, and knowledge reciprocity in the process of knowledge internal and external transformation. The results show that:

- Good trust and communication between governments are the basis of the knowledge learning effect. The key to the formation of the knowledge synergy effect is to enhance the complementarity of the knowledge structure among governments and give way to the interests of non-focus governments. The two kinds of government ability of cooperative knowledge development determine the strength of the knowledge reciprocity effect. With the increase of the knowledge effect, focus governments and non-focus governments will maintain a positive-peer state.

- The increase of tacit knowledge exchange cost will restrain the effect of knowledge learning. If the two kinds of governments form a relatively closed concept of knowledge utilization, overemphasize higher-value knowledge, enhance protection, and the infrastructure of knowledge utilization is not in place and the knowledge transformation platform is overcrowded, it will lead to the weakening of the knowledge spillover effect. With the attenuation of the two kinds of knowledge effects, focus government and non-focus government will stabilize the negative-peer state.

- The more active the knowledge transformation activities within the two types of government, the stronger the ability to mine their knowledge, which will inhibit the willingness of knowledge interaction and lead to the formation of a negative-peer state.

- The higher the opportunity income of the two types of intergovernmental external knowledge transformation activities, the greater the restriction of knowledge protection, and the higher the degree of punishment of the central government on knowledge closure behavior, the stronger the binding force of intergovernmental cooperation contract will be, promoting the formation of a positive-peer state.

- The knowledge learning effect only exists in the early and middle stages of green governance. When the willingness to manage is high, the effect of learning is limited. When the difference of management intention is large, both sides' enthusiasm to 
participate in the collaborative transformation of knowledge increases, but because the high willing side bears too much cost, the collaborative relationship may break down.

- The knowledge spillover effect plays an important role in the later stage of green governance. With the increase of the capacity gap, the knowledge acceptance and transformation of non-focus government spillovers are limited, limiting the knowledge spillover effect. When peer interaction is positive, knowledge spillover will bring benefits. Therefore, the following suggestions were put forward in this paper:

- Improve the efficiency of external knowledge absorption and strengthen the perception of external knowledge. The non-focus government should take the initiative to get close to the focus government, learn from the other party's green governance will, optimize the knowledge structure of management ability, and improve the elasticity of complementary knowledge stock. The non-focus government should make the proportion of low knowledge cooperative income distribution and the flexibility of knowledge stock properly and gain more knowledge income through increased overall interests. The non-focus government should actively absorb the focus government's management talents, open the exchange of posts and enterprises, and improve the absorption capacity of external explicit and tacit knowledge.

- $\quad$ Reduce the cost of knowledge outflow and avoid the collaborative crisis caused by knowledge 'private possession.' In knowledge learning, the cost of observation and communication should be controlled reasonably. In knowledge spillover, optimize the knowledge docking channels and platform space, reduce the occupancy of knowledge conversion platforms, share common experience, planning, and schemes, and enhance all governments' behavior enthusiasm. The regional government should form a unified program document and build a platform for knowledge transformation across regions. The green development policies of local governments can be seamlessly linked and a shared government platform can be established to gradually eliminate the constraints of geography on development.

- Correctly guide the internal knowledge transformation process. Through internal knowledge transformation, some governments increase knowledge increment significantly and obtain more knowledge increment benefits. However, the government should take a long-term view, reasonably evaluate the situation of its knowledge increment in the region and clarify the opportunity loss of knowledge investment and the damage of knowledge protection punishment to its interests. As far as the green development environment is concerned, restrictive punishment measures can be implemented to reduce the bad behaviors of 'free-riding' and the belief that 'knowledge is not open'.

- Create an excellent positive-peer environment and improve the local government audit and guidance mechanism. The central government should assess the local government's decision-making situation in time and regulate the bad behavior reasonably. The government should pay attention to the good government images and reputations, encourage local cooperation, and curb the relatively closed government behavior and refusal to exchange knowledge.

- Local governments should be encouraged to choose the appropriate group state, ensuring that their development is not biased, decisions are not blind, and management is followed. The non-focus government, if it is not encouraged, can enter into a positivepeer state. Non-focus government can use the knowledge learning effect in the early stage to increase the willingness of green governance, promote the improvement of management ability with the help of the transfer of internal tacit knowledge to explicit knowledge, and then enter the period of rapid green development with the help of the knowledge spillover effect. As for the focus governments, they are not encouraged to choose to lead actively. In the early stage, the non-focus government's awareness of green governance is weak, relying on the focus government's unilateral wake-up effect, which is low and easy to undermine their own positive will. The non-focus government can gradually lead the regional collaborative governance and take the 
initiative to carry out knowledge spillover in the middle and later stages by following independently. Therefore, this paper encourages the formation of negative-peer, consistent-direction-peer, reverse-peer, and positive-peer development paths. All kinds of companion states are reasonable and necessary. The government should rationally analyze the path of green governance decision-making to formulate appropriate development plans.

The article examines green governance in China from the perspectives of central and local governments, focus and non-focus governments, but the following shortcomings still exist: (1) The ultimate landing point of the government's green governance is still on the green innovative enterprises. The article only considers the impact of the peer effects among local governments on green governance, and subsequent studies can add the role of enterprises. (2) In terms of methodology, the article adopts a two-party evolutionary game approach. In subsequent studies, green innovation enterprises can be added to build a three-party evolutionary game model to analyze the government's green governance behavior more comprehensively.

Author Contributions: H.L. proposed the topic, designed the research content, and revised the final version of the paper. P.Y. participated in revising and editing the paper. X.W. and J.H. were involved in the simulation analysis and writing of the thesis. L.Y. provided guidance during the writing of the paper. All authors have read and agreed to the published version of the manuscript.

Funding: This research was funded by Program of Shanghai Planning Office of Philosophy and Social Science of China (No. 2020BGL023).

Institutional Review Board Statement: Not applicable.

Informed Consent Statement: Not applicable.

Data Availability Statement: Not applicable.

Conflicts of Interest: The authors declare no conflict of interest.

\section{References}

1. Rong, L.; Bi, K. A study on the comprehensive carrying capacity and spatial optimization under the new development concept-an empirical study of shandong province. E3S Web Conf. 2020, 199, 00005. [CrossRef]

2. Li, W.; Zhang, Y. Family control, political connection, and corporate green governance. Sustainability 2020, 12, 7068. [CrossRef]

3. Dieng, B.; Pesqueux, Y. On 'green governance'. Int. J. Sustain. Dev. 2017, 20, 111. [CrossRef]

4. Kusis, J.; Brokane, L.; Miltovica, B. Green Governance Principles in the Development of Environmental Educational Infrastructure. Auzina Rural Dev. Entrep. Bioecon. Prod. Co-Oper. Agric. 2017, 4, 256-266.

5. Mackenzie, A.; Pearson, L.J; Pearson, C.J. A framework for governance of public green spaces in cities. Landsc. Res. 2019, 44, 444-457. [CrossRef]

6. Yuan, L.; Cui, X. Green Governance Innovation in Government: Connotations, Situation and Strategic Options. Chin. Public Adm. 2016, 11, 151-154.

7. Yang, L.; Liu, H. Green Governance: The Way to Build a Beautiful China. Chin. Public Adm. 2014, 29, 291-314.

8. Fay, M.; Wang, J.Z.; Draugelis, G.; Deichmann, U. Role of green governance in achieving sustainable urbanization in china. China World Econ. 2014, 22, 19-36. [CrossRef]

9. Liao, K.; Dai, S.; Duan, X. Research on the Coordination Effect Evaluation and Dynamic Relationship of Technological Innovation and Green Governance. Sci. Technol. Prog. Policy 2019, 36, 34-43.

10. Huang, Y.; Aguilar, F.; Yang, J.; Qin, Y.; Wen, Y. Predicting citizens' participatory behavior in urban green space governance: Application of the extended theory of planned behavior. Urban For. Urban Green. 2021, 1, 127110. [CrossRef]

11. Wang, C. A Study of the Cooperative Dynamic Mechanism among Governments for Transregional Green Governance. Shandong Soc. Sci. 2020, 6, 124-129.

12. Tan, H.; Thurbon, E.; Kim, S.Y. Overcoming incumbent resistance to the clean energy shift: How local governments act as change agents in coal power station closures in China. Energy Policy 2021, 149, 112058. [CrossRef]

13. He, S. A study on the Coordination Mechanism and Policy System of Environmental Governance and Green Development in the Yangtze River Economic Belt. Contemp. Econ. Manag. 2019, 41, 57-63.

14. Jain, M.; Siva, V.; Hoppe, T. Assessing governance of low energy green building innovation in the building sector: Insights from Singapore and Delhi. Energy Policy 2020, 145, 111752. [CrossRef]

15. Pineda-Guerrero, A.; Escobedo, F.J.; Carriazo, F. Governance, Nature's Contributions to People, and Investing in Conservation Influence the Valuation of Urban Green Areas. Land 2020, 10, 14. [CrossRef] 
16. Ding, G. Green Development and Modernization of National Governance Capacity-A Review of the Third Forum on the Construction of National Governance System and Governance Capacity. J. Huazhong Univ. Sci. Technol. (Soc. Sci. Ed.) 2017, 31, 138-140.

17. Li, W.; Zhang, Y.; Zheng, M. Research on Green Governance of Chinese Listed Companies and Its Evaluation. Manag. World 2019, $35,126-133+160$.

18. Poier, S. Clean and Green-The Volkswagen Emissions Scandal: Failure of Corporate Governance? Probl. Ekorozw. 2020, 15, 33-39. [CrossRef]

19. Wang, Y.; Chen, H. Leading Green Governance with Green Development: Change of Concepts, Reasons for Transformation and Selection of Strategies. J. Sichuan Univ. (Philos. Soc. Sci. Ed.) 2019, 3, 45-52.

20. Torres, C.; Olvera-Vargas, L.A.; Gómez, J.S. Discovering innovation opportunities based on SECI model: Reconfiguring knowledge dynamics of the agricultural artisan production of agave-mezcal, using emerging technologies. J. Knowl. Manag. 2020, 6, 1-12. [CrossRef]

21. Bonaccorsi, A.; Piccaluga, A. A Theoretical Framework for the Evaluation of University-Industry Relationships. $R$ D Manag. 1994, 24, 229-247. [CrossRef]

22. Koschatzky, K. Networking and Knowledge Transfer Between Research and Industry in Transition Countries: Empirical Evidence from the Slovenian Innovation System. J. Technol. Transf. 2002, 27, 27-38. [CrossRef]

23. Sun, C.; Li, C. The influence of Trans-industry Organizational Ties on Innovation Performance-Double Moderating of Heterogeneity of Knowledge and Absorptive Capacity. Soft Sci. 2019, 33, 42-46+59.

24. Horvat, D.; Dreher, C.; Som, O. How Firms Absorb External Knowledge-Modelling and Managing the Absorptive Capacity Process. Int. J. Innov. Manag. 2019, 23, 217-230. [CrossRef]

25. Carayannis, E.G.; Alexander, J.; Ioannidis, A. Leveraging knowledge, learning, and innovation in forming strategic governmentuniversity-industry (GUI) R\&D partnerships in the US, Germany, and France. Technovation 2000, 20, 477-488.

26. Xing, Q.; Shangguan, D.; Liang, X. Knowledge Sharing Considered the Multidimensional Attributes of Knowledge and Its Governance Model in Collaborative Innovation. Soft Sci. 2016, 30, 50-54+59.

27. Ahmed, Y.A.; Ahmad, M.N.; Ahmad, N. Social Media for Knowledge-Sharing: A Systematic Literature Review. Telemat. Inform. 2018, 37, 72-112. [CrossRef]

28. Zhang, J.M.; Jiang, H.; Wu, R. Reconciling the Dilemma of Knowledge Sharing: A Network Pluralism Framework of Firms' R\&D Alliance Network and Innovation Performance. J. Manag. 2019, 45, 2635-2665.

29. Zhou, M.; Govindan, K.; Xie, X.B. How fairness perceptions, embeddedness, and knowledge sharing drive green innovation in sustainable supply chains: An equity theory and network perspective to achieve sustainable development goals. J. Clean. Prod. 2020, 260, 120950. [CrossRef]

30. Pan, H.; Chen, J.; Yang, C. Peer Effect of Family Business Violation. J. Shanxi Univ. Financ. Econ. 2020, 42, 87-98.

31. Curtius, H.C.; Hille, S.L.; Berger, C. Shotgun or snowball approach? Accelerating the diffusion of rooftop solar photovoltaics through peer effects and social norms. Energy Policy 2018, 118, 596-602. [CrossRef]

32. Feng, G.; Wang, J. The Peer Effect of Corporate Innovation in Social Network. Chin. J. Manag. 2019, 16, $1809-1819$.

33. Anonymous. Hot technologies: Focusing government resources for more effective innovation. Strateg. Dir. 2008, 24, 32-34. [CrossRef]

34. Kong, Y.; Feng, C.; Yang, J. How does China manage its energy market? A perspective of policy evolution. Energy Policy 2020, 147, 111898. [CrossRef]

35. Khan, S.A.R.; Sharif, A.; Golpra, H. A Green Ideology in Asian Emerging Economies: From Environmental Policy and Sustainable Development. Sustain. Dev. 2019, 27, 1063-1075. [CrossRef]

36. Loughran, K. Urban parks and urban problems: An historical perspective on green space development as a cultural fix. Urban Stud. 2018, 57, 2321-2338. [CrossRef]

37. Hoe, S.L. Tacit Knowledge, Nonaka and Takeuchi SECI Model and Informal Knowledge Processes. Int. J. Organ. Theory Behav. 2006, 9, 490-502. [CrossRef]

38. Shao, C.; Ding, D.H. Study on Schroumldinger's Cat in SECI Model and Its Theoretical Explanation. China Ind. Econ. 2009.

39. Harorimana, D. The Impact of Culture on the Application of the SECI Model. BioMed Central 2010, 8, $152-161$.

40. Sakellariou, E.; Karantinou, K.; Goffin, K. "Telling tales": Stories, metaphors and tacit knowledge at the fuzzy front-end of NPD. Creat. Innov. Manag. 2017, 26, 353-369.

41. Farnese, M.L.; Barbieri, B.; Chirumbolo, A. Managing Knowledge in Organizations: A Nonaka's SECI Model Operationalization. Front. Psychol. 2019, 10, 2730. [CrossRef] [PubMed]

42. Richtnér, A.; Ahlstrom, P.; Goffin, K. “Squeezing R\&D”: A Study of Organizational Slack and Knowledge Creation in NPD, Using the SECI Model. J. Prod. Innov. Manag. 2014, 31, 1268-1290.

43. Nonaka, I.; Toyama, R.; Konno, N. SECI, Ba and Leadership: A Unified Model of Dynamic Knowledge Creation. Long Range Plan. 2000, 33, 5-34. [CrossRef]

44. Wu, Y.; Senoo, D.; Magnier-Watanabe, R. Diagnosis for organizational knowledge creation: An ontological shift SECI model. J. Knowl. Manag. 2010, 14, 791-810. [CrossRef]

45. Sarin, S.; Mcdermott, C. The Effect of Team Leader Characteristics on Learning, Knowledge Application, and Performance of Cross-Functional New Product Development Teams. Decis. Sci. 2003, 34, 707-739. [CrossRef] 
46. Post, C.; Rahman, N. Green governance: Boards of directors' composition and environmental corporate social responsibility. Bus. Soc. 2011, 12, 58-72. [CrossRef]

47. Hsieh, H.C.; Claresta, V.; Bui, T. Green building, cost of equity capital and corporate governance: Evidence from us real estate investment trusts. Sustainability 2020, 12, 3680. [CrossRef]

48. Bush, L.; Kring, T.J.; Ruberson, J.R. Suitability of greenbugs, cotton aphids, and heliothis virescens eggs for development and reproduction of orius insidiosus. Entomol. Exp. Appl. 2011, 67, 217-222. [CrossRef]

49. Gea-Bermúdez, J.; Jensen, I.G.; Münster, M.; Oivisto, M.K.; Ravn, H. The role of sector coupling in the green transition: A least-cost energy system development in northern-central europe towards 2050. Appl. Energy 2021, 289, 116685. [CrossRef]

50. Khovanskaia, M.; Ivanyi, Z. Possibilities and options for the clean development mechanism and the green investment scheme in central and eastern europe: Macedonian and romanian perspectives. Nat. Resour. Forum 2010, 31, 1-10. [CrossRef]

51. Sano, J.; Inami, S.; Seimiya, K.; Ohba, T.; Sakai, S.; Takano, T. Effects of green tea intake on the development of coronary artery disease. Circ. J. 2003, 68, 665-670. [CrossRef] [PubMed]

52. Shah, K.U.; Arjoon, S.; Rambocas, M. Aligning corporate social responsibility with green economy development pathways in developing countries. Sustain. Dev. 2016, 24, 237-253. [CrossRef]

53. Tupas, F.P. Green governance-an integrated programs of local government units: A case of northern iloilo, philippines. Indian J. Sci. Technol. 2020, 13, 2686-2699. [CrossRef]

54. Radzi, A.; Darus, F.; Yusoff, H.; Hermawan, A. Green-based governance and external pressure: Do they influence environmental disclosure? empirical evidence from ISO 14001 companies in malaysia. Humanit. Soc. Sci. Rev. 2020, 8, 974-984.

55. Lin, G. Promoting green electricity development from industrial to developing countries: What needs to be done? Environ. Politics 2002, 11, 184-191.

56. Phillip, H.P.; Theodore, P. Knowledge Creation in Strategic Alliances: Another Look at Organizational Learning. Asia Pac. J. Manag. 2000, 17, 201-222.

57. Claudine, S.; Paul, H. Exploration and exploitation: The interplay between knowledge and continuous innovation. Int. J. Technol. Manag. 2008, 42,1-2.

58. Liu, L.; Zhang, T. The Evolution Game Analysis on Organization Tactic Knowledge Transferring-Based on the Reciprocal E nterprise Environments. J. Tech. Econ. Manag. 2011, 21, 38-41.

59. Coll, J.C.M.; Hirshleifer, J. The Limits of Reciprocity: Solution Concepts and Reactive Strategies in Evolutionary Equilibrium Models. Ucla Econ. Work. Pap. 1989, 3, 1378-1379. [CrossRef] 